\title{
Efficient hierarchically structured composites containing cobalt catalyst for clean synthetic fuel production from Fischer-Tropsch synthesis
}

\author{
Yuefeng Liu ${ }^{\mathrm{a}, *}$, Jingjie Luo $^{\mathrm{b}}$, Maria Girleanu ${ }^{\mathrm{b}}$, Ovidiu Ersen ${ }^{\mathrm{b}}$, Cuong Pham-Huu ${ }^{\mathrm{a}, *}$, Christian Meny ${ }^{\mathrm{b}}$ \\ ${ }^{a}$ Institut de Chimie et Procédés pour l'Energie, l'Environnement et la Santé (ICPEES), UMR 7515 CNRS-University of Strasbourg, ECPM, 25, rue Becquerel, 67087 Strasbourg \\ Cedex 02, France \\ ${ }^{\mathrm{b}}$ Institut de Physique et Chimie des Matériaux de Strasbourg (IPCMS), UMR 7504 CNRS-University of Strasbourg, 23, rue du Loess, 67034 Strasbourg Cedex 02, France
}

\section{A R T I C L E I N F O}

\section{Article history:}

Received 17 February 2014

Revised 8 August 2014

Accepted 9 August 2014

Available online 3 September 2014

\section{Keywords:}

Fischer-Tropsch synthesis

Clean fuel

Hierarchical structure

Titanium dioxide

Cobalt nanoparticles

Carbon nanotubes

${ }^{59}$ Co zero field NMR

\begin{abstract}
A B S T R A C T
We report a straightforward preparation method to synthesize hierarchical composite consisting of $\mathrm{TiO}_{2}$ coated multi-walled carbon nanotubes (CNTs) decorating a macroscopic host structure of $\alpha-\mathrm{Al}_{2} \mathrm{O}_{3}$. The obtained composite possesses moderate specific surface area and very open porous structure, as well as moderate interaction with active sites, which significantly improve the cobalt nanoparticles dispersion and the mass diffusion during the reaction. The $\mathrm{Co} / \mathrm{TiO}_{2} / \mathrm{CNT}-\alpha-\mathrm{Al}_{2} \mathrm{O}_{3}$ (CoTiCNTA) catalyst is then used in the Fischer-Tropsch synthesis (FTS) process. This hierarchical catalyst achieves a FTS rate to $\mathrm{C}_{5+}$ of $0.80 \mathrm{~g}_{\mathrm{C} 5+} \mathrm{g}_{\text {cat }}{ }^{-1} \mathrm{~h}^{-1}$ along with a long-chain hydrocarbons $\left(\mathrm{C}_{5_{+}}\right)$selectivity of $85 \%$, which can be pointed out as the most outstanding noble promoter-free catalyst for the FTS process. The as-synthesized catalyst also exhibits an extremely high stability as a function of time on stream which is also one of the prerequisites for the development of future FTS catalysts, especially for the Biomass-to-Liquids process where trace amount of impurities and/or moisture could have an impact on the catalyst stability. The present work also introduces a new investigation methodology based on the use of zero field ${ }^{59} \mathrm{Co}$ NMR, which allows one to map in a precise manner the cobalt active phase distribution and to correlate it with the FTS performance. It is expected that such technique would be extremely helpful for the understanding of the catalyst structure-performance relationship and for future optimization in the FTS process as well as in other fields of investigation where cobalt particles are involved.
\end{abstract}

(C) 2014 Elsevier Inc. All rights reserved.

\section{Introduction}

The demands for energy and goods did increase sharply during the last decades due to the fast industrial growth of the emergent countries like China and India and also to the increase of the world population. In the same time, the oil reserves are decreasing and their production rate is close to reaching its maximum before facing a decline [1,2]. Thus, sustainable and environment friendly energy production and consumption are becoming key challenges of this century. The new developments of promoting low- $\mathrm{CO}_{2}$ footprint technologies need to consider the alternative feedstock, such as natural gas, charcoal and biomass [3,4]. It is worth noting that no pressure will come from natural gas and coal in the near future as large resources of these raw materials still exist. The FischerTropsch synthesis (FTS) is a key technology in the more global $\mathrm{X}$-To-Liquids (XTL) processes which allow the transformation of

* Corresponding authors. Fax: +33 368852674

E-mail addresses: yuefeng.liu@unistra.fr (Y. Liu), cuong.pham-huu@unistra.fr (C. Pham-Huu). synthesis gas $\left(2 \mathrm{H}_{2}+\mathrm{CO}\right)$ into liquid hydrocarbons followed by a hydrocracking of the heavy fraction into useful compounds such as naphtha, diesel, jet fuel, and lubricant [5-10]. The liquid fuels produced by FTS are aromatic, nitrogen, and sulfur-free which will greatly contribute to reduction of the pollution resulting from the transportation sector. In addition, FTS could allow the development of a more environmental friendly process such as the Biomass-to-Liquids (BTL) in regard to reduction of the carbon footprint [11].

According to earlier studies, FTS activity and selectivity are influenced by the support physical properties like specific surface area, pore volume, and pore size distribution in addition to the support material itself $[12,13]$. The nature of the support plays a crucial role in the properties of the final Fischer-Tropsch catalyst; indeed, the activity is indirectly affected by the support nature. Moreover, under conditions favoring chain growth, site-time yields and stability on supported cobalt catalysts are traditionally considered to be independent of cobalt dispersion and support identity [14-20]. The selectivity of long-chain hydrocarbons $\left(C_{5+}\right)$ depends significantly on the reactor temperature profile, and thus, the 
selection for appropriate catalysts and carriers should obey several rules: good thermal conductivity of the support [21]; low pressure drop along the catalyst bed [22,23]; effective utilization of all active sites present in the catalyst, along with appropriate macroscopic structure of the support that favors the evacuation of the products and provides high accessibility to the reactants [22]. Previous results revealed that the opened porous structure of the nanofibrous $\gamma-\mathrm{Al}_{2} \mathrm{O}_{3}$ could enhance the specific activity and stability in FTS reaction by providing high metallic cobalt dispersion and enhancing the CO diffusion to the active sites [24,25]. Thus, it is of interest to develop new type of carbon-based support with high accessibility and good thermal conductivity in the highly exothermal Fischer-Tropsch synthesis. Chin et al. [26] explored the FeCrAlY foam covered with aligned multiwall carbon nanotube arrays as microchannel support containing Co-Re active sites for FTS. The catalyst with such structure, especially resulting from the hierarchical CNT, provided larger surface area for anchoring active sites, high thermal conductivity and enhanced mass transfer by the larger interstitials. Many studies have also demonstrated that the growth of carbon nanotubes/nanofibers on macroporous host structures could provide efficient contact between active sites and reactants, improving thermal conductivity along with better mass transfer throughout the catalyst body [27-30]. The carbon nanofibers were grown onto carbon-felts (FB-CNF/carbon-felt) host structure synthesized by Zarubova et al. [29] using the method of chemical vapor deposition (CVD) leading to the formation of carbon composite support with high BET surface area $\left(>280 \mathrm{~m}^{2} / \mathrm{g}\right)$ and unique hierarchical structure. The cobalt supported on this kind of composite (Co/FB-CNF/carbon-felt) showed a very uniform reaction temperature during the FTS reaction [29]. This type of composites were even coated by a layer of $\mathrm{SiO}_{2}$, presenting a relatively uniform temperature through the reactor and stable catalytic activity [31].

We have previously found that thermally conductive support $(\beta-\mathrm{SiC})$ matrix doped with $\mathrm{TiO}_{2}$ exhibits a medium metal-support interaction with cobalt nanoparticles and leads to the formation of small cobalt particles with enhanced FTS activity compared to the same catalyst supported on undoped SiC support [32]. It is expected that the $\mathrm{TiO}_{2}$ phase not only participates in the increase of the cobalt dispersion [32-34], but also interacts with the active phase to prevent the motion of the nanoparticles or even the deactivation by sintering during FTS test $[35,36]$. However, to date, there has been no reports on the utilization of $\mathrm{TiO}_{2}$ promoted hierarchically structured composite for the FTS reaction. Herein, we explore an efficient strategy based on the use of hierarchically structured composites promoted with $\mathrm{TiO}_{2}$ in order to combine high mass transfer and good thermal conductivity with highly dispersed cobalt catalyst. The FTS results obtained have shown that the catalyst exhibits a relatively high FTS activity along with a high selectivity toward long-chain hydrocarbons and also displays an extremely high resistance toward deactivation.

\section{Experimental section}

\subsection{Synthesis of hierarchically structured composites}

The $\alpha$-alumina support (Sasol) was crushed and sieved, and a fraction of $150-400 \mu \mathrm{m}$ was retained for catalyst preparation. The catalyst was prepared using an aqueous solution of $\mathrm{Fe}$ $\left(\mathrm{Fe}\left(\mathrm{NO}_{3}\right)_{3} \cdot 9 \mathrm{H}_{2} \mathrm{O}\right.$, Aldrich) and $\mathrm{Co}\left(\mathrm{Co}\left(\mathrm{NO}_{3}\right)_{2} \cdot 6 \mathrm{H}_{2} \mathrm{O}\right.$, Aldrich $)$ precursor, respectively. The various metal mass loadings of either iron or cobalt can be found in Table 1 to adjust the CNT growth yield. The wet solid was dried in an oven at $110^{\circ} \mathrm{C}$ and then calcined in air at $350{ }^{\circ} \mathrm{C}$ for $2 \mathrm{~h}$. The carbon nanotubes (CNTs) were synthesized by a chemical vapor deposition (CVD) method $[37,38]$. The residual catalyst was expected to be completely encapsulated within a graphene overlayers according to our previous work [37] and is no longer accessible to the reactants during the FTS experiments.

The 10 wt.\% $\mathrm{TiO}_{2}$ nanoparticles loaded on the structured materials were prepared by pore volume impregnation. Typically, $5 \mathrm{~g}$ of as-synthesized materials were impregnated with $5 \mathrm{~mL}$ absolute ethanol containing $1.97 \mathrm{~g} \mathrm{Ti}\left(\mathrm{iOC}_{3} \mathrm{H}_{7}\right)_{4}$ (Aldrich). After impregnation, the samples were allowed to dry at room temperature for $4 \mathrm{~h}$ and then dried in an oven at $110^{\circ} \mathrm{C}$ in air for $8 \mathrm{~h}$. The transformation of the precursor into $\mathrm{TiO}_{2}$ crystalline phase was performed in argon at $600{ }^{\circ} \mathrm{C}$ for $5 \mathrm{~h}$ with a heating rate of $2^{\circ} \mathrm{C} / \mathrm{min}$.

\subsection{Catalyst preparation}

The cobalt loading was set at $10 \mathrm{wt}$ \% for all catalysts. The real cobalt mass content was analyzed by inductively coupled plasma (ICP) technique and the results can be found in Table 2 . In this process, the cobalt phase was deposited onto the supports via pore volume impregnation method using an ethanol-water (50:50 v:v) solution containing cobalt nitrate. The as-prepared materials (typically $5 \mathrm{~g}$ ), either with $\mathrm{TiO}_{2}$ or not, were impregnated by $7 \mathrm{~mL}$ of ethanol-water solution to which $2.74 \mathrm{~g} \mathrm{Co}\left(\mathrm{NO}_{3}\right)_{2} \cdot 6 \mathrm{H}_{2} \mathrm{O}$ was added. After impregnation, the solid was allowed to dry at room temperature for $2 \mathrm{~h}$ and then oven-dried at $110^{\circ} \mathrm{C}$ for $8 \mathrm{~h}$. The solid was calcined in air at $300^{\circ} \mathrm{C}$ for $2 \mathrm{~h}$ in order to decompose the nitrate into its corresponding oxide. The oxide form was further reduced in flowing hydrogen $\left(30 \mathrm{~mL} \mathrm{~g}_{\text {cat }}^{-1} \mathrm{~min}^{-1}\right)$ at $350{ }^{\circ} \mathrm{C}$ for $6 \mathrm{~h}$. In order to prevent excessive air oxidation during the exposure of the catalyst, a passivation process was performed before discharging of the catalyst (surface passivation was carried out with a mixture of $1 \mathrm{vol} . \% \mathrm{O}_{2}$ diluted in helium at room temperature). The obtained reduced catalysts are noted as CoTiCNTA and CoCNTA for the one supported on the $\mathrm{TiO}_{2}$-promoted and $\mathrm{TiO}_{2}$-free hierarchical structure of alumina decorated with carbon nanotubes, respectively, and CoTiA and CoA for the one supported on alumina promoted with $\mathrm{TiO}_{2}$ or pure alumina, respectively.

\subsection{Characterization techniques}

Thermogravimetric analysis (TGA) was carried out on a Setaram apparatus with an air flow rate of $25 \mathrm{~mL} \mathrm{~min}^{-1}$ and a heating rate of $10^{\circ} \mathrm{C} \mathrm{min}^{-1}$, from room temperature to $1000^{\circ} \mathrm{C}$. The textural properties of materials were characterized on a Tristar Micromeritics sorptometer using nitrogen as adsorbent at $-196{ }^{\circ} \mathrm{C}$. The morphology of the solid was examined by scanning electron microscopy (SEM) on a JEOL 6700-FEG microscope. X-ray diffraction (XRD) measurements were carried out on a Bruker D-8 Advance diffractometer $\left(2 \theta=10-80^{\circ}\right)$ with a $\mathrm{Cu} \mathrm{K} \alpha$ radiation. X-ray photoelectron spectroscopy (XPS) measurements of the support were performed on a MULTILAB 2000 (THERMO VG) spectrometer equipped with $\mathrm{Al} \mathrm{K} \alpha$ anode $(h v=1486.6 \mathrm{eV})$ with 10 min of acquisition. Temperature-programed reduction (TPR) profiles were carried out at atmospheric pressure in a U-shaped tubular quartz reactor in an Autochem II (Micromeritics). The calcined catalysts $(100 \mathrm{mg})$ were exposed to a diluted hydrogen flow (5 vol.\% $\mathrm{H}_{2}$ in argon) with a heating rate of $10^{\circ} \mathrm{C} \mathrm{min}^{-1}$ from room temperature to $900{ }^{\circ} \mathrm{C}$.

Conventional and scanning transmission electron microscopy analyses were performed on a JEOL $2100 \mathrm{~F}$ (S)TEM electron microscope operating at $200 \mathrm{kV}$ beam voltage and equipped with a Cscorrected condenser allowing to reach a resolution of $0.11 \mathrm{~nm}$ in STEM. The STEM mode is based on scanning a sample by a focused electron probe and detecting high-angle scattered electrons using an annular dark-field detector (HAADF) [39]. Indeed, in the HAADF-STEM technique, the proportionality between the intensity 
Table 1

Synthesis conditions and physical characteristics of the CNT-decorated $\alpha-\mathrm{Al}_{2} \mathrm{O}_{3}$ composites with various CNT loadings.

\begin{tabular}{|c|c|c|c|c|c|c|}
\hline Sample & Catalyst & Syn. temp. $\left({ }^{\circ} \mathrm{C}\right)$ & Yield (\%) & Surface area $\left(\mathrm{m}^{2} \mathrm{~g}^{-1}\right)$ & Total pore volume $\left(\mathrm{cm}^{3} \mathrm{~g}^{-1}\right)$ & Average pore diameter $(\mathrm{nm})^{\mathrm{a}}$ \\
\hline A & - & - & - & 5.0 & 0.011 & 8 \\
\hline B & 2 wt.\% Co & 750 & 4 & 11.1 & 0.053 & 19 \\
\hline $\mathrm{C}$ & $2 \mathrm{wt} . \% \mathrm{Fe}$ & 750 & 12 & 18.4 & 0.051 & 11 \\
\hline $\mathrm{D}$ & $4 \mathrm{wt} . \% \mathrm{Fe}$ & 750 & 26 & 27.0 & 0.106 & 16 \\
\hline $\mathrm{E}$ & 2 wt.\% $\mathrm{Co}+2$ wt.\% Fe & 750 & 73 & 76.0 & 0.199 & 11 \\
\hline
\end{tabular}

${ }^{\text {a }} D_{\text {pore }}=4 V / S$, where $S$ is surface area and $V$ is pore volume.

Table 2

Structure and textural properties of cobalt supported on hierarchically structured composites.

\begin{tabular}{|c|c|c|c|c|c|c|}
\hline Catalyst & $\mathrm{Co}^{0}$ loading (wt.\%) ${ }^{\mathrm{a}}$ & $S_{\mathrm{BET}}\left(\mathrm{m}^{2} / \mathrm{g}\right)$ & $V_{\text {total }}\left(\mathrm{cm}^{3} / \mathrm{g}\right)$ & $D_{\text {pore }}(\mathrm{nm})^{\mathrm{b}}$ & $d_{\mathrm{XRD}}\left(\mathrm{Co}^{0}\right)(\mathrm{nm})^{\mathrm{C}}$ & $d_{\mathrm{NMR}}\left(\mathrm{Co}^{0}\right)(\mathrm{nm})^{\mathrm{d}}$ \\
\hline $\mathrm{CoA}$ & $10.4 \pm 0.5$ & 7 & 0.02 & - & $35 \pm 3$ & 18 \\
\hline CoTiA & $9.6 \pm 0.6$ & 9 & 0.03 & - & $30 \pm 3$ & - \\
\hline CoCNTA & $10.7 \pm 0.5$ & 62 & 0.25 & 16 & $20 \pm 3$ & 14 \\
\hline CoTiCNTA & $10.3 \pm 0.5$ & 71 & 0.25 & 14 & $23 \pm 3$ & 12 \\
\hline
\end{tabular}

a Cobalt mass content is confirmed by inductively coupled plasma (ICP) technique.

b $D_{\text {pore }}=4 V / S$, where $S$ is surface area and $V$ is pore volume.

${ }^{c} d_{\mathrm{XRD}}\left(\mathrm{Co}^{0}\right)=0.75 \times d\left(\mathrm{Co}_{3} \mathrm{O}_{4}\right)$, the cluster size of cobalt oxides was calculated from XRD peaks at $2 \theta=36.9^{\circ}$ by using the $\mathrm{Scherrer}$ formula for $\mathrm{Co}_{3} \mathrm{O}_{4}$ on the calcined catalysts $[50,51]$.

${ }^{\mathrm{d}}$ Particle size was calculated based on the ${ }^{59}$ Co NMR results of the cobalt atoms fraction engaged in the different blocking temperature ranges.

and nuclear charge is typically equal to $Z^{1.8}$ which allows obtaining a good contrast in the corresponding images, in order to investigate elements with large difference between their atomic number, such as metallic nanoparticles deposited on a lighter element support. For (S)TEM analysis, several droplets of powdered material suspended in ethanol by sonication were deposited onto a cooper grid covered by a holey carbon membrane. The camera length used in HAADF mode was $10 \mathrm{~cm}$, corresponding to inner and outer diameters of the annular detector of $60 \mathrm{mrad}$ and $160 \mathrm{mrad}$.

${ }^{59} \mathrm{Co}$ zero field nuclear magnetic resonance $\left({ }^{59} \mathrm{Co}\right.$ NMR) experiments were performed in a homemade zero magnetic field spectrometer. Detailed description of the technique can be found in the literature $[40,41]$. The integrated spin-echo intensity was recorded every $1 \mathrm{MHz}$ using broadband pulsed NMR spectrometer with phase-sensitive detection. NMR spectra were taken at five different values of the excitation RF field power, covering a range over more than one order of magnitude. The analysis was performed on the tested catalyst covered with a homogeneous solid wax layer in order to prevent any surface oxidation of the cobalt phase during air exposure.

\subsection{Fischer-Tropsch synthesis (FTS)}

The FTS reaction was performed in a tubular fixed-bed stainless steel reactor $(7 \mathrm{~mm}$ i.d.) with circulating silicon oil as heating source. Typically, reduced catalysts (i.e., $2.5 \mathrm{~g}$ with a macroscopic size ranged between 0.15 and $0.40 \mathrm{~mm}$ ) were deposited between quartz wool plugs in the middle of the reactor. The reactor pressure was slowly increased from 1 to 40 bar (ramping rate of $10 \mathrm{bar} \mathrm{h}^{-1}$ ) under argon via a back pressure regulator (MFI Ltd.). At 40 bar, the reactor temperature was raised from room temperature to the initial reaction temperature $\left(215^{\circ} \mathrm{C}\right)$, with the heating rate of $2{ }^{\circ} \mathrm{C} \mathrm{min}^{-1}$. Then, the argon flow was replaced by a 50:50 v:v mixture of synthesis gas (syngas, $\mathrm{H}_{2} / \mathrm{CO}$ molar ratio of 2 ) and argon. The catalyst was activated under a syngas-argon mixture with different syngas concentrations before being evaluated under pure syngas condition. The catalyst bed temperature was monitored with a thermocouple $(\varnothing 0.3 \mathrm{~mm})$ inserted inside a stainless steel finger $(\varnothing 1 \mathrm{~mm})$ passing through the catalyst bed. The products were condensed in two high pressure traps maintained at $85^{\circ} \mathrm{C}$ and $15^{\circ} \mathrm{C}$, respectively. The outlet gases $\left(C_{1}-C_{6}\right.$ hydrocarbons, and $\mathrm{CO}_{2}$ as well as $\mathrm{Ar}$ and unconverted $\mathrm{CO}$ ) were analyzed on-line, both by thermal conductivity detector (TCD) and flame ionization detector (FID), by a gas chromatography (GC). The GC Varian 3800 equipped with a Carbobond capillary (TCD, $30 \mathrm{~m} \times 0.53 \mathrm{~mm}$, thickness of stationary phase of $10 \mu \mathrm{m}$ ) and DP-1 (FID, thickness of stationary phase of $1.5 \mu \mathrm{m}$ ) columns. $\mathrm{C}_{1}-\mathrm{C}_{4}$ hydrocarbons and $\mathrm{CO}_{2}$ were quantitative analyzed, the $\mathrm{C}_{5+}$ selectivity $\left(\mathrm{S}_{\mathrm{C}^{+}}\right)$is calculated as follows:

$S_{\mathrm{C}_{5+}}=1-\sum_{i=1}^{4} S_{c_{i}}-S_{\mathrm{CO}_{2}}$

The liquid phase and water were condensed in the high and low temperature $\left(85^{\circ} \mathrm{C}\right.$ and $\left.15^{\circ} \mathrm{C}\right)$ traps and were analyzed off-line at the end of the test. A known amount $(100 \mathrm{mg})$ of the organic phase, liquid hydrocarbons, and waxy products was dissolved in $3 \mathrm{~mL}$ of dichloromethane under sonication during $30 \mathrm{~min}$. Then $20 \mathrm{~mL}$ of $\mathrm{CS}_{2}$ (Acros) was added to the solution in order to ensure complete dissolution of the organic phase. For analysis, $1 \mu \mathrm{L}$ of the solution was injected in a GC apparatus equipped with a Simdist column operated at $400{ }^{\circ} \mathrm{C}$, which allows the detection of hydrocarbons from $\mathrm{C}_{9}$ to $\mathrm{C}_{70}$.

\section{Results}

\subsection{Preparation of hierarchically structured composites}

The SEM micrographs of $\alpha-\mathrm{Al}_{2} \mathrm{O}_{3}$ loaded with different weight of CNTs are presented in Figs. 1 and S1. The yield of CNTs on the alumina host matrix is confirmed by thermogravimetric analysis (Fig. 1D). The results indicate that the $\alpha-\mathrm{Al}_{2} \mathrm{O}_{3}$ surface is not completely covered by the CNT network when the CNTs yield is below 26 wt.\% (Figs. 1 and S1). As it can be seen in Fig. $1 \mathrm{C}$, the $\alpha-\mathrm{Al}_{2} \mathrm{O}_{3}$ composite with CNTs loading of $73 \mathrm{wt} . \%$ is constituted by a thin shell of homogeneous, highly entangled, and structure-opened carbon nanotubes network that exhibits full accessibility and relatively high specific surface area of $76 \mathrm{~m}^{2} \mathrm{~g}^{-1}$. The corresponding $\mathrm{N}_{2}$ adsorption-desorption data are listed in Table 1 . The results show that the BET surface area increases as a function of the CNTs yield. We also found remarkable growth rate of the CNTs on the Co-Fe alloy ( 2 wt.\% Co +2 wt.\% Fe). The CNTs growth rate over this catalyst is almost three times higher than that obtained on the 

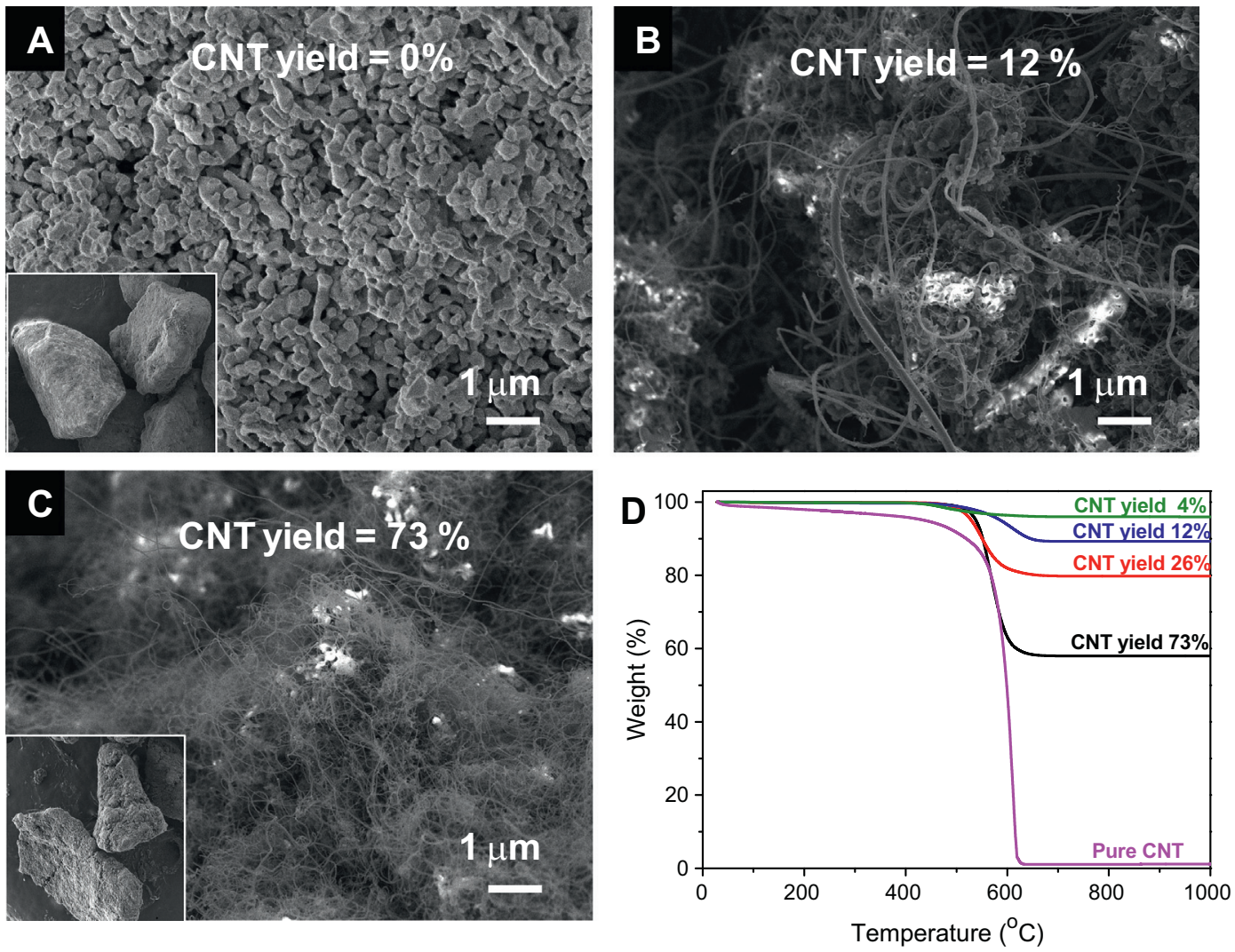

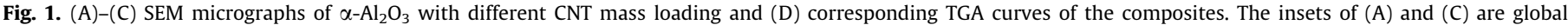
micrographs of $\alpha-\mathrm{Al}_{2} \mathrm{O}_{3}$ and CNT-decorated $\alpha-\mathrm{Al}_{2} \mathrm{O}_{3}$ grains.

catalyst with only 4 wt.\% Fe. The surface area of pure $\alpha-\mathrm{Al}_{2} \mathrm{O}_{3}$ is only about $5 \mathrm{~m}^{2} \mathrm{~g}^{-1}$, and thus, it is expected that CNTs (CNTs surface area is about $189 \mathrm{~m}^{2} \mathrm{~g}^{-1}$ after purification [42]) are the primary contributor to the overall surface area of the final composite. Thus, for the $12 \mathrm{wt} . \%$ CNTs yield the surface area associated with the CNTs can be estimated to be $0.11 \times 189=20 \mathrm{~m}^{2} \mathrm{~g}^{-1}$, which generally matches the measured value $\left(18.4 \mathrm{~m}^{2} \mathrm{~g}^{-1}\right)$. Similarly, the theoretical value of surface area should be $79.8 \mathrm{~m}^{2} \mathrm{~g}^{-1}$ with $73 \mathrm{wt} . \%$ CNTs yield. The difference between the real and estimated specific surface area of the CNT-decorated $\alpha-\mathrm{Al}_{2} \mathrm{O}_{3}$ composite should result from the closed caps on the synthesised composite, while most of them should be opened in the purified CNT during acid treatment [43]. It is expected that a large part of the cobalt particles will be deposited on the CNTs surface due to the presence of oxygenated functional groups [37] which play the role of anchoring sites.

The higher catalytic activity along with an extremely high selectivity toward liquid hydrocarbons is obtained on the CNT-decorated alumina $\left(\mathrm{CNTs}-\alpha-\mathrm{Al}_{2} \mathrm{O}_{3}\right)$ catalyst compared to pristine $\alpha-\mathrm{Al}_{2} \mathrm{O}_{3}$ or CNTs supported cobalt catalysts, according to the results of our previous work [30]. In this study, the CNT-decorated alumina composite with $73 \mathrm{wt} . \%$ yield of CNTs, grown from the Co-Fe bimetallic catalyst, is applied as the support for synthesizing the $\mathrm{TiO}_{2}$-based catalyst. The $\mathrm{N}_{2}$ adsorption-desorption results are detailed in Fig. 2A and Table S1. The specific surface area of alumina undergoes huge increase after the introduction of CNTs as mentioned above, from $5 \mathrm{~m}^{2} \mathrm{~g}^{-1}$ for $\alpha-\mathrm{Al}_{2} \mathrm{O}_{3}$ to $76 \mathrm{~m}^{2} \mathrm{~g}^{-1}$ for CNTs- $\alpha-\mathrm{Al}_{2} \mathrm{O}_{3}$. Titania addition causes a slight change of the surface area and pore diameter, i.e., $72 \mathrm{~m}^{2} \mathrm{~g}^{-1}$ and $15 \mathrm{~nm}$ for $\mathrm{TiO}_{2} /$ $\mathrm{CNT}-\alpha-\mathrm{Al}_{2} \mathrm{O}_{3}$ instead of $76 \mathrm{~m}^{2} \mathrm{~g}^{-1}$ and $11 \mathrm{~nm}$ for CNT- $\alpha-\mathrm{Al}_{2} \mathrm{O}_{3}$, respectively (Table $\mathrm{S} 1$ ). The enhancement of the interparticle mass transport is mostly linked with the presence of large pores in the alumina-based support. The formation of carbon nanotubes inside these macropores will provide anchorage sites for dispersing the cobalt metal nanoparticles but will not modify in a large extend the average macropore size. The macroporosity of $\alpha-\mathrm{Al}_{2} \mathrm{O}_{3}$ and $\mathrm{TiO}_{2}-\alpha-\mathrm{Al}_{2} \mathrm{O}_{3}$ supports was carried out by mercury intrusion porosimetry and the results are presented in Fig. 2B. As it can be seen in Fig. $2 \mathrm{~B}$, the volume of macropores $(50-1000 \mathrm{~nm}$ ) measured by $\mathrm{Hg}$ intrusion of $\alpha-\mathrm{Al}_{2} \mathrm{O}_{3}$ and $\mathrm{TiO}_{2}-\alpha-\mathrm{Al}_{2} \mathrm{O}_{3}$ supports is 0.46 and $0.37 \mathrm{~cm}^{3} / \mathrm{g}$, respectively. The total pore volume determined by $\mathrm{N}_{2}$ sorption is less than $10 \%$ of the total pore volume measured by $\mathrm{Hg}$ intrusion. It is expected that these macropores will participate in a large extend to the enhancement of the mass transport during the FTS reaction [24].

XRD patterns of the supports are presented in Fig. 2C, which confirm the presence of both CNTs and $\mathrm{TiO}_{2}$, in the composites, along with diffraction lines corresponding to the alumina support. The XRD patterns presented in Fig. $2 \mathrm{C}$ (b and d) only show crystalline anatase phase which indicates high selectivity toward formation of anatase phase during the thermal treatment process. Typical XPS survey of $\mathrm{TiO}_{2} / \mathrm{CNT}-\alpha-\mathrm{Al}_{2} \mathrm{O}_{3}$ composite and high-resolution spectrum of $\mathrm{TiO}_{2}$ (inset) are displayed in Fig. 2D. The survey scan of the $\mathrm{TiO}_{2} / \mathrm{CNT}-\alpha-\mathrm{Al}_{2} \mathrm{O}_{3}$ reveals the presence of elements such as $\mathrm{Ti}, \mathrm{C}$, and $\mathrm{Al}$, corresponding to the different phases in the composite. The photoelectron peak for Ti $2 \mathrm{p}_{1 / 2}$ and Ti $2 \mathrm{p}_{3 / 2}$ in the hierarchically structured $\mathrm{TiO}_{2} / \mathrm{CNT}-\alpha-\mathrm{Al}_{2} \mathrm{O}_{3}$ composite is clearly located at binding energies of 465.6 and $459.7 \mathrm{eV}$, respectively. The peak separation of $5.9 \mathrm{eV}$ between the Ti $2 \mathrm{p}_{1 / 2}$ and Ti $2 \mathrm{p}_{3 / 2}$ signals can be assigned to a normal state of $\mathrm{Ti}^{4+}$ in the anatase $\mathrm{TiO}_{2}$, which is in excellent agreement with the reported literature values [44].

The low-resolution TEM micrograph of CNT- $\alpha-\mathrm{Al}_{2} \mathrm{O}_{3}$ composite (Fig. S2) demonstrates that the synthesis method was extremely selective toward the formation of carbon nanotubes and neither 

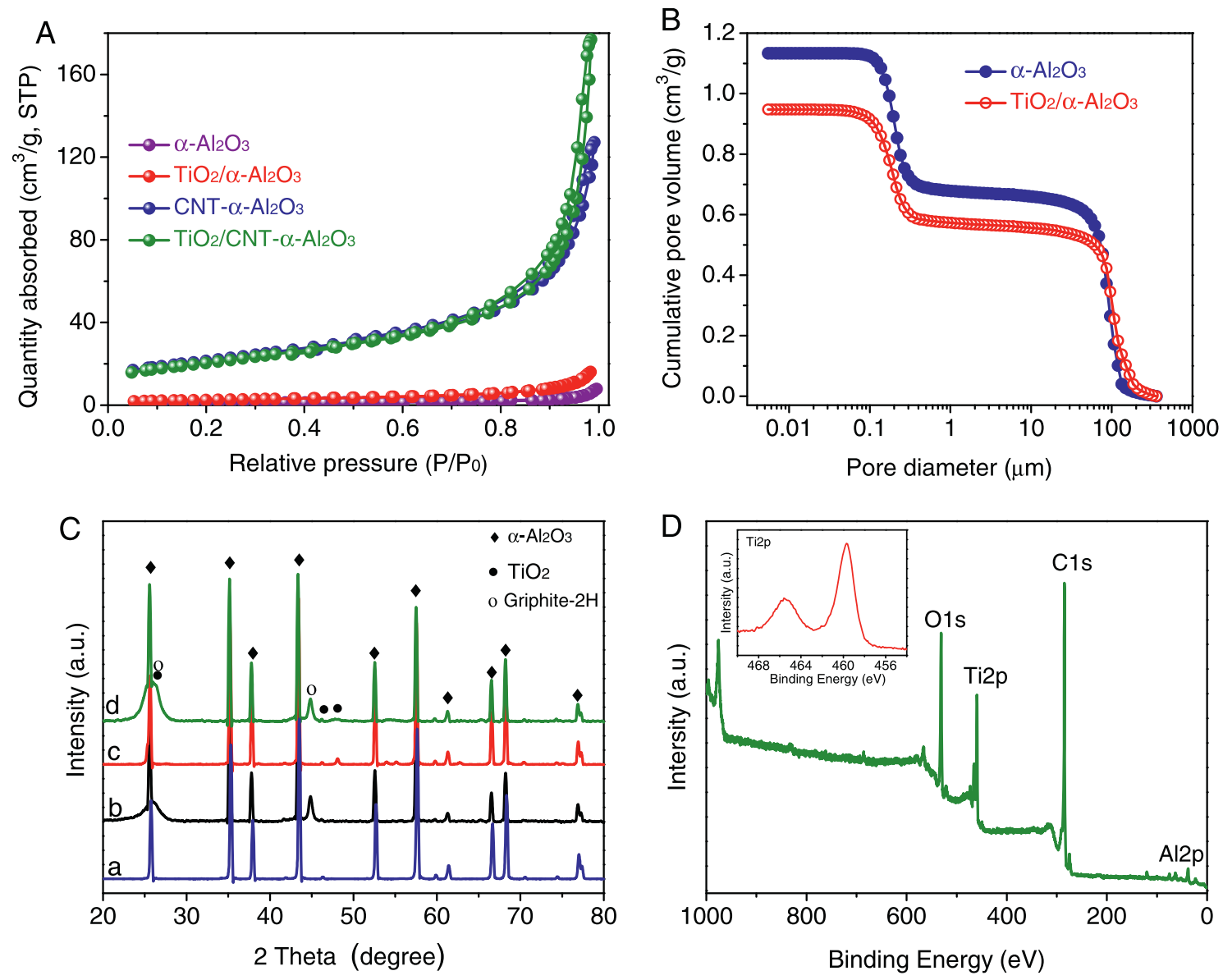

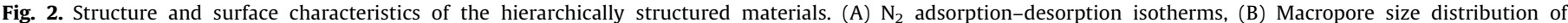

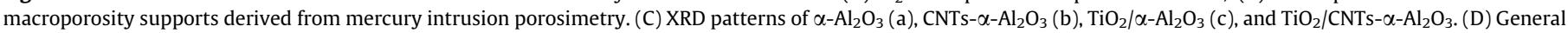
scanning XPS spectrum of $\mathrm{TiO}_{2} / \mathrm{CNT}-\alpha-\mathrm{Al}_{2} \mathrm{O}_{3}$, the inset is the high-resolution XPS spectrum of Ti $2 \mathrm{p}$ peaks in (D) showing the present of anatase TiO ${ }_{2}$ nanoparticles.

carbon nanoparticles nor amorphous carbon was observed inside the composite [38]. The $\alpha-\mathrm{Al}_{2} \mathrm{O}_{3}$ matrix (indicated by the white arrow) is covered by a highly entangled CNT network as shown in Fig. S2A. High-resolution TEM micrograph of $\mathrm{CNT}-\alpha-\mathrm{Al}_{2} \mathrm{O}_{3}$ in Fig. S2B shows the residual catalyst particles (indicated by the red arrows) which were embedded within several graphene layers. These metallic particles are inaccessible, neither to the acid medium during the purification process, nor to any gaseous reactants during the subsequent use of the composite, due to the presence of the graphene layer wrapping their surface [38]. Thus, these residual Fe-Co particles are expected to barely influence the FTS reaction performance [30]. In order to ascertain that these particles will not influence the NMR data, we also analyzed by NMR the grown nanotubes without the FTS catalysts. ${ }^{59}$ Co NMR spectra are compared with those of the cobalt-based catalysts. The ${ }^{59} \mathrm{Co}$ NMR spectra of the CNT- $\alpha-\mathrm{Al}_{2} \mathrm{O}_{3}$ support and reduced catalysts are presented in Fig. 3. The NMR peaks located at higher frequency ( $>280 \mathrm{MHz}$ ) on $\mathrm{CNT}-\alpha-\mathrm{Al}_{2} \mathrm{O}_{3}$ support and on the different catalysts, either promoted by $\mathrm{TiO}_{2}$ or not (CoCNTA and CoTiCNTA), are attributed to the cobalt particles embedded by graphene layers (Fig. 3). For comparison, at the same experimental conditions, the NMR spectrum of $\alpha-\mathrm{Al}_{2} \mathrm{O}_{3}$-supported cobalt catalyst (CoA) is also presented in Fig. 3b. However, no NMR spin echo peak higher than $270 \mathrm{MHz}$ is observed, which confirms that the NMR peak at high frequency was directly associated with the encapsulated growth catalyst (Co-Fe alloy) or $\mathrm{Co}^{2+}$ ions as mentioned in Ref. [45]. Since no NMR peak in the frequency range of the FTS catalysts (200$240 \mathrm{MHz}$ ) has been observed in the $\mathrm{CNT}-\alpha-\mathrm{Al}_{2} \mathrm{O}_{3}$ support, it

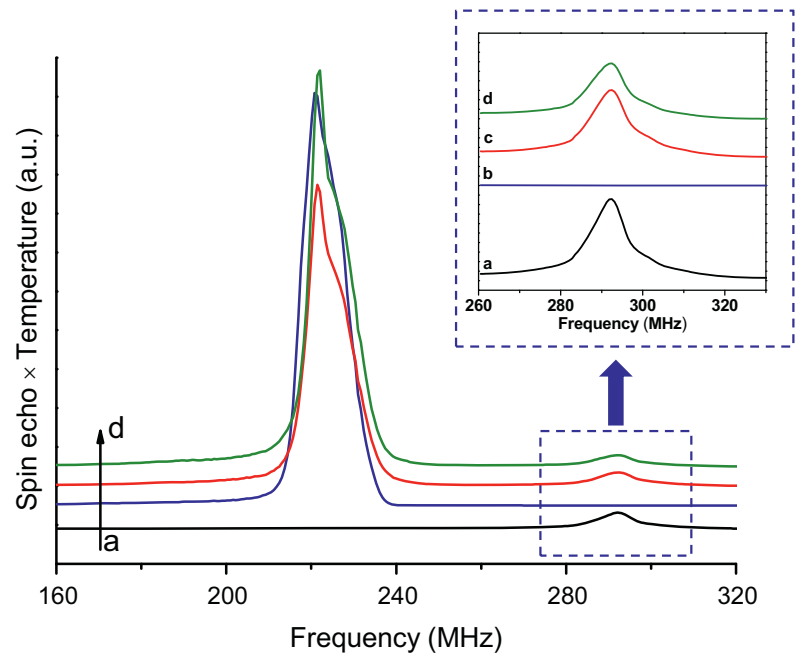

Fig. 3. ${ }^{59} \mathrm{Co}$ NMR spectra of grown carbon nanotube and cobalt on $\alpha-\mathrm{Al}_{2} \mathrm{O}_{3}$ recorded at liquid helium temperature $\left(4.2 \mathrm{~K}\right.$ ). (a) $\mathrm{CNT}-\alpha-\mathrm{Al}_{2} \mathrm{O}_{3}$, (b) $\mathrm{CoA}$, (c) CoCNTA, and (d) CoTiCNTA.

ascertains that our NMR data interpretations will not be influenced by the presence of the CoFe catalysts used to grow the CNTs.

As shown in the SEM image (Fig. 4A), as-prepared hierarchical $\mathrm{TiO}_{2} / \mathrm{CNT}-\alpha-\mathrm{Al}_{2} \mathrm{O}_{3}$ is composed of bare rocky mountain-like $\alpha$ $\mathrm{Al}_{2} \mathrm{O}_{3}$ matrix and a thin shell of a homogeneous vegetation-like 

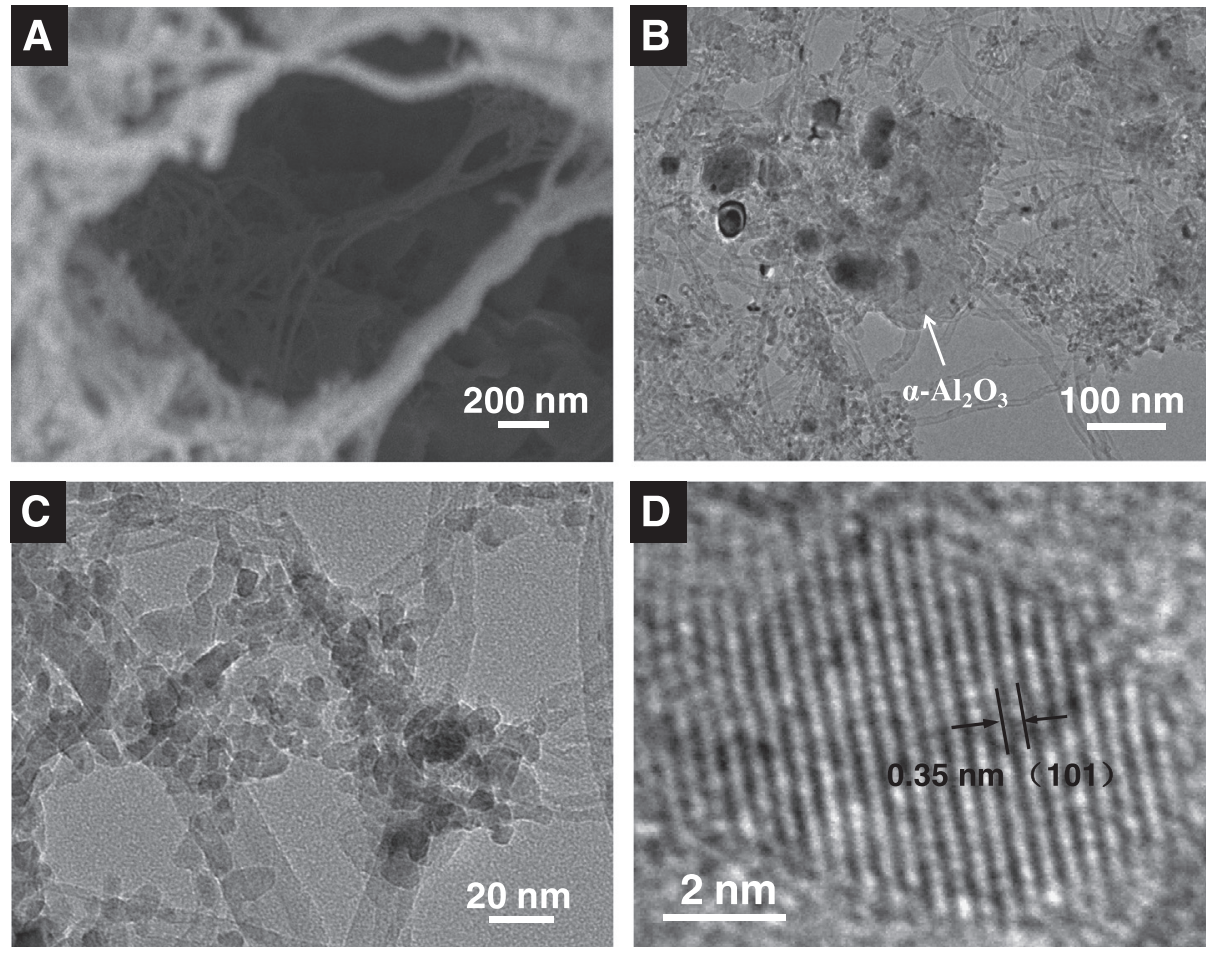

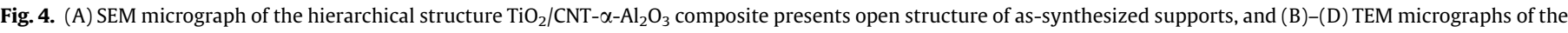
composite show the high dispersion of the $\mathrm{TiO}_{2}$ nanoparticles on the CNTs surface.

carbon nanotube decorated with $\mathrm{TiO}_{2}$ nanoparticles. This open structure will play an efficient role to enhance the diffusion of reactants $\left(\mathrm{CO}\right.$ and $\mathrm{H}_{2}$ ) toward the active site and also facilitate the products evacuation from the catalyst to the gas phase medium, which will greatly contribute to an increase in the liquid hydrocarbon selectivity [20]. The TEM image of the $\mathrm{TiO}_{2} / \mathrm{CNT}-\alpha-\mathrm{Al}_{2} \mathrm{O}_{3}$ composite is shown in Fig. 4B. It can be seen that the surface of the asgrown CNTs and $\alpha-\mathrm{Al}_{2} \mathrm{O}_{3}$ are well covered by $\mathrm{TiO}_{2}$ nanoparticles with a relatively homogeneous size. The TEM micrograph in Fig. 4C clearly evidences the high coverage of CNT network by the $\mathrm{TiO}_{2}$ nanoparticles, which could be attributed to the high effective surface area of the CNTs and defect sites present on the CNT surface. The medium-resolution TEM of $\mathrm{TiO}_{2}$ nanoparticles on the CNT surface also clearly shows that the $\mathrm{TiO}_{2}$ nanoparticles anchored on the CNT wall possess homogeneous dispersion. The corresponding lattice fringes are clearly observed in Fig. 4D, and the interplanar spacing is around $0.35 \mathrm{~nm}$ for the $\mathrm{TiO}_{2}$-promoted hierarchically structured composite, corresponding to the (101) crystal face in the anatase phase.

\subsection{Characteristics of the cobalt-containing catalysts}

The reducibility of the cobalt-based catalysts has been investigated by temperature-programed reduction $\left(\mathrm{H}_{2}-\mathrm{TPR}\right)$, and the corresponding results are displayed in Fig. S3. After the addition of $\mathrm{TiO}_{2}$, the reducibility of cobalt-based catalyst barely changes. The reduction peak located at around $310-330{ }^{\circ} \mathrm{C}$ is attributed to the reduction of $\mathrm{CO}_{3} \mathrm{O}_{4}$ to $\mathrm{CoO}[46,47]$, which is overlapped with the other reduction peak. The following reduction peaks of $\mathrm{CoA}$ and CoTiA catalysts, located around $367^{\circ} \mathrm{C}$ and $370{ }^{\circ} \mathrm{C}$, respectively, are mainly originating from the reduction of $\mathrm{CoO}$ to $\mathrm{Co}^{0}$ [48]. The hierarchically structured catalyst displays broader and overlapped reduction peaks. The peak located at around $400{ }^{\circ} \mathrm{C}$ could also be attributed to the reduction of $\mathrm{CoO}$. The reduction peak around $500{ }^{\circ} \mathrm{C}$ could be assigned to the gasification of carbon nanotubes that is partly catalyzed by the presence of the cobalt particles. Similar results have already been reported by Khodakov and co-workers [49] over the cobalt deposited on multi-walled carbon nanotubes.

The main textural properties of the ex-situ reduced catalysts are listed in Table 2, which displays different tendencies for both the surface area and pore volume compared to the bare supports. The specific surface area of the alumina-based catalysts (CoA and CoTiA) remains almost unchanged after cobalt deposition, due to the presence of large pores inside the support that are hardly affected by the deposited cobalt particles. The BET surface area of the CoCNTA catalyst slightly decreases from $76 \mathrm{~m}^{2} \mathrm{~g}^{-1}$ to $62 \mathrm{~m}^{2} \mathrm{~g}^{-1}$ (Table 2) after deposition of the cobalt active phase. The slight decrease in the surface area of the CoCNTA catalyst after cobalt addition could be attributed to the high effective surface area of the CNT network and the complete absence of any ink-bottled pores within the composite material. Indeed, it has been reported that for supports with micropores or small mesopores a large surface area loss can be observed after depositing an active phase due to the problem of pore plugging by the cobalt active phase [52]. The $\mathrm{TiO}_{2}$-added catalyst with hierarchical structure shows slightly higher specific surface and the same total pore volume compared with $\mathrm{TiO}_{2}$-free hierarchically structured catalyst.

SEM image and EDX mapping (Fig. S4) confirm the uniform deposition of promoter ( $\mathrm{Ti}$ ) and active species ( $\mathrm{Co}$ ) onto the hierarchical structure. TEM images of the hierarchically structured CoTiCNTA catalyst reveal that cobalt particles interact with the $\mathrm{TiO}_{2}$ phase on graphene wall of CNTs (Figs. 5 and S5). The resolved inter-planar distance is 0.34 and $0.35 \mathrm{~nm}$, which correspond to the (002) plane of carbon and the (101) plane of $\mathrm{TiO}_{2}$, respectively (Fig. 5C). High-resolution HAADF-STEM (Fig. 5D) and energy dispersive X-ray spectroscopy (EDS) (Fig. S5C) further confirm the cobalt nanoparticles location on the surface of $\mathrm{TiO}_{2}$. The typical particle size of cobalt situated on the $\mathrm{TiO}_{2}$ surface is around $2 \mathrm{~nm}$. 

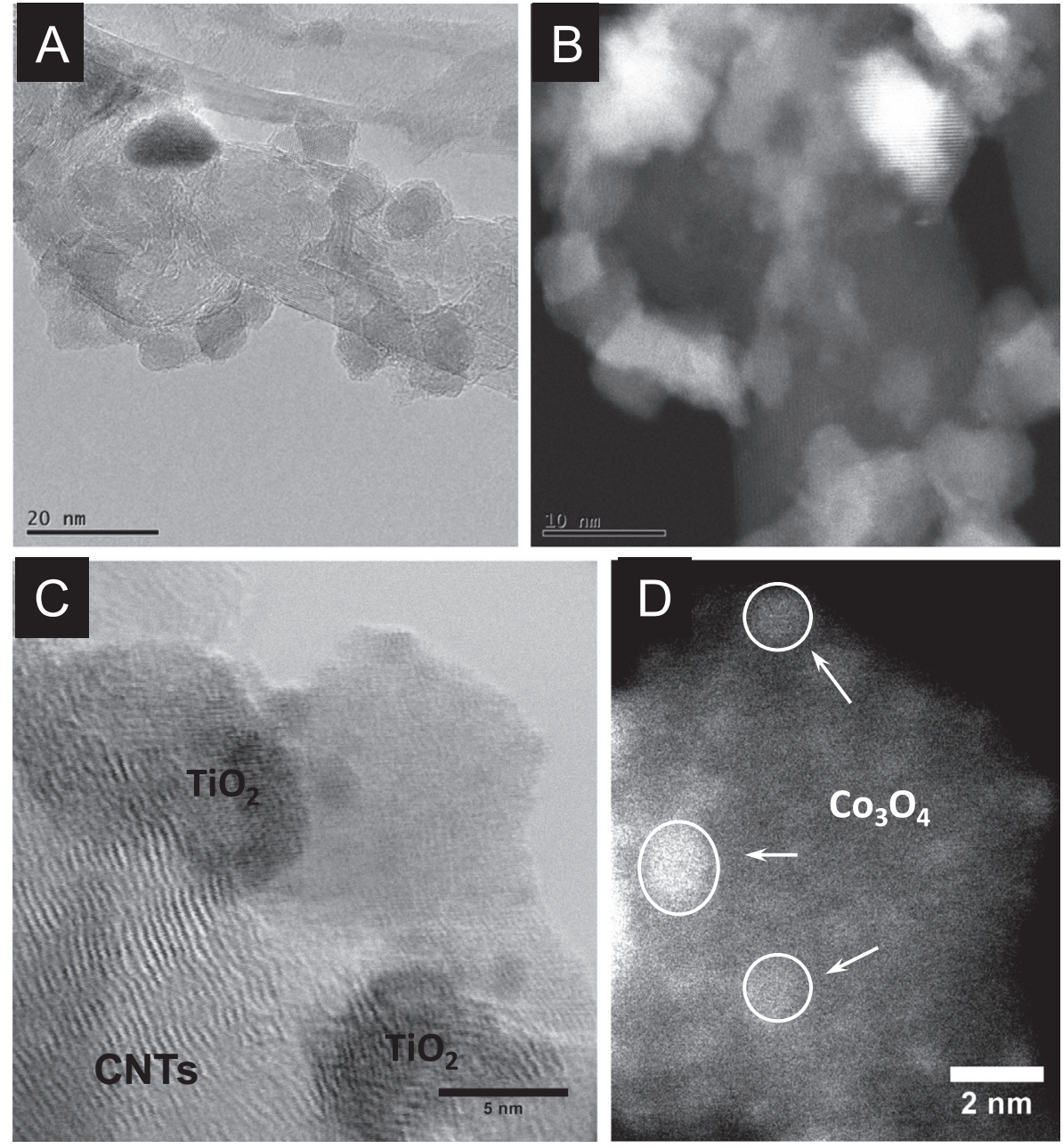

Fig. 5. (A) and (C) Typical TEM images and (B) and (D) HAADF-STEM images of CoTiCNTA (the cobalt oxide on TiO ${ }_{2}$ surfaces are marked with white circles).

The cobalt particle size was determined by two techniques, XRD line broadening and ${ }^{59} \mathrm{Co}$ NMR, and the results are presented in Table 2. As one can see a relatively large discrepancy is observed in the cobalt particle size determined by XRD and NMR techniques. Such discrepancy could be attributed to the fact that the XRD technique is mostly sensitive to the large cobalt particles, and thus, in a sample with a large particle size distribution, the average particle size is not very accurately determined by such technique. Indeed, while NMR line width is not sensitive to the size of the particles, XRD line width is strongly sensitive to the size of the crystallites. For narrow size distribution, XRD and NMR would result in similar particle sizes but this is not the case in the samples under investigation. In XRD of the smallest particles will almost not contribute to the sample XRD line width (wide and low amplitude contribution) while they fully contribute to the NMR spectra. Therefore the XRD particle average size can only be an overestimate of the average particle size, and the broader the size distribution the larger the overestimate. The analyses reported in the NMR section show that at most $60 \%$ of the total Co mass is engaged in less than $1 \%$ of the large cobalt particles. These very few particles will dominate the XRD pattern (XRD is a mass average) while the $40 \%$ of the mass split into much smaller particles will almost not be included in the XRD analyses. In NMR, all Co atoms are taken into account whatever the size of the particles in which they are embedded. This is why we believe that the discrepancy between XRD and NMR techniques can be very significant and usually results to an overestimate of the particle size by XRD line width analyses.

\subsection{Fischer-Tropsch synthesis}

The catalytic performance under steady-state conditions over macroporous and hierarchically structured catalysts is presented in Table 3. The $\mathrm{CO}_{2}$ detection limit of our GC is about $0.1 \%$ according to the calibration using a diluted $\mathrm{CO}_{2}$ in helium. The $\mathrm{CO}_{2}$ selectivity for all the catalysts is less than $0.2 \%$, indicating that the water-gas shift reaction does not occur over these cobalt-based catalysts. The selectivity to $\mathrm{C}_{5+}$ hydrocarbons of all catalysts fall in the range of $92-95 \%$ (Tables 3 and S2). Ti-promoted cobalt catalysts are much more active in FTS than the un-doped ones. Besides, the $\mathrm{TiO}_{2}$ based hierarchically structured catalyst exhibits the highest activity among all the tested catalysts (Table 3). Carbon monoxide conversion increases from about $17.7 \%$ over conventional $\mathrm{Co} / \alpha-\mathrm{Al}_{2} \mathrm{O}_{3}(\mathrm{CoA})$ to $33.4 \%$ on the $\mathrm{Co} / \mathrm{TiO}_{2}-\alpha-\mathrm{Al}_{2} \mathrm{O}_{3}$ (CoTiA) macroporous catalyst. The $\mathrm{TiO}_{2}$-promoted hierarchically structured catalyst (CoTiCNTA) exhibits a carbon monoxide conversion of $44.3 \%$, which is also much higher than that obtained over the conventional hierarchical catalyst $(28.2 \%$, CoCNTA). The results of catalytic evaluation are consistent with the characterization data, indicative of the much better cobalt dispersion when $\mathrm{TiO}_{2}$ was introduced to the hierarchical composite support. The carbon balance of the different experiments is $90 \pm 4 \mathrm{wt}$.\%. The difference between the theoretical and experimental carbon balance could be explained from several facts: (i) the error margin of the CO flow rate which could be accounted to about $5 \pm 2 \mathrm{wt} . \%$, and (ii) the liquid hydrocarbons, especially those in the range of $C_{6}$ to $C_{8}$, that 
Table 3

Comparison of the FTS catalytic performance of the hierarchically structured Titania/Carbon Nanotubes $/ \alpha$ - $\mathrm{Al}_{2} \mathrm{O}_{3}$ composites-supported cobalt catalysts. ${ }^{\text {a }}$

\begin{tabular}{|c|c|c|c|c|c|c|c|}
\hline \multirow[t]{2}{*}{ Catalyst } & \multirow[t]{2}{*}{ CO conversion (\%) } & \multicolumn{3}{|c|}{ Product selectivity (\%) } & \multirow[t]{2}{*}{ CoTY $^{c}$} & \multirow[t]{2}{*}{ TOF $^{d}$} & \multirow[t]{2}{*}{$\alpha^{\mathrm{e}}$} \\
\hline & & $\mathrm{CH}_{4}$ & $\mathrm{C}_{2}-\mathrm{C}_{4}$ & $\mathrm{C}_{5+}$ & & & \\
\hline $\mathrm{CoA}$ & 17.7 & 3.3 & 1.9 & 94.8 & 2.6 & 28.8 & 0.92 \\
\hline $\mathrm{CoTiA}^{\mathrm{b}}$ & 33.4 & 3.7 & 2.2 & 94.1 & 5.0 & - & 0.92 \\
\hline CoCNTA & 28.2 & 4.2 & 3.6 & 92.1 & 4.2 & 37.2 & 0.91 \\
\hline CoTiCNTA & 44.3 & 3.3 & 2.0 & 94.7 & 6.6 & 48.7 & 0.92 \\
\hline
\end{tabular}

a All data were obtained after $20 \mathrm{~h}$ of time on stream where stable catalytic performance under testing conditions was achieved. Reaction conditions: reaction temper-

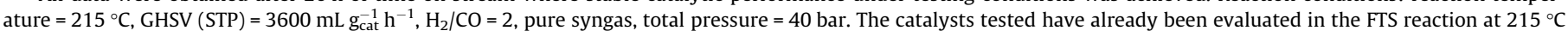
for about three days.

b $2.5 \mathrm{~g}$ of catalysts were diluted with $2.5 \mathrm{~g}$ of $\mathrm{SiC}(150-400 \mu \mathrm{m})$.

c Cobalt Time Yield (CoTY, $10^{-5} \mathrm{~mol}_{\mathrm{co}} \mathrm{g}_{\mathrm{Co}}^{-1} \mathrm{~s}^{-1}$, molar CO conversion rate per gram of Co per hour).

d Turnover frequency (TOF), $10^{-3} \mathrm{~s}^{-1}$, moles of converted CO per surface atom of cobalt particles and per second. The cobalt dispersion ( $D$, \%) [53] based on the cobalt average particles size $(d, \mathrm{~nm})$ from ${ }^{59}$ Co NMR by the formula: $D=96 / d$.

e Chain growth probability factor $(\alpha)$.

were lost during the waxes recovery which were accounted to about $5 \pm 2$ wt.\%. Indeed, part of these hydrocarbons was condensed inside the traps and the totality was not detected by the gas chromatography while for the liquid analysis only hydrocarbons higher than $C_{9}$ were detected. The relatively low carbon balance in the present work is due to the lost of the $C_{6}-C_{8}$ fractions during the heating of the trap. The amount of the $C_{6}-C_{8}$ fractions was monitored by GC analysis of the trap during the depressurization and heating, and the value of $5 \mathrm{wt} . \%$ is obtained. The chain growth probability reported in the present work is determined from $C_{10}$ to $C_{50}$, and thus, it is expected that such distribution is hardly impacted by the $C_{6}$ to $C_{8}$ fractions (ca. 5 wt.\%) which is partly lost during the wax recovery process. We have also re-calculated the ASF plot, with and without the $\mathrm{C}_{6}-\mathrm{C}_{8}$ fractions lost during the heating of the trap, and the results were hardly changed (Table 3). In addition, the selectivity in the present article is reported on the basis of $\mathrm{C}_{5+}$, and thus, it is expected that such selectivity will be even higher than the one reported if all the $C_{6}-C_{8}$ fractions are included in the calculation.

Catalytic performance for the reaction temperature of $215^{\circ} \mathrm{C}$ suggests that $\mathrm{TiO}_{2}$ addition significantly enhances the FTS activity of catalyst under the same reaction conditions. The FTS activity improvement in the presence of $\mathrm{TiO}_{2}$, regardless of the support nature, i.e., $\alpha$-alumina or $\alpha$-alumina decorated with CNTs, could be directly attributed to the improvement of the dispersion of the cobalt particles leading to the formation of more small cobalt particles consecutive to the high metal-support interaction with the deposited $\mathrm{TiO}_{2}$ phase. The high improvement of FTS activity on the CoTiCNTA catalyst could also be attributed to the combining effect between $\mathrm{TiO}_{2}$ and CNTs with high effective surface area and short diffusion length. The impact of reaction temperature on the catalytic behavior for the FTS reaction will be investigated in detail in the following work.

The $\mathrm{CO}$ conversion and $\mathrm{C}_{5+}$ selectivity obtained on the CoTiA and CoTiCNTA catalysts as a function of the reaction temperature under a relatively high GHSV, $4800 \mathrm{~mL} \mathrm{~g}_{\mathrm{cat}}{ }^{-1} \mathrm{~h}^{-1}$ (STP), are displayed in Fig. S6. The FTS rate steadily increases over both catalysts with increasing reaction temperature, whereas $S_{\mathrm{C} 5+}$ selectivity remains relatively high at more than $90 \%$ on both catalysts. The FTS rate on the CoTiCNTA catalyst remains higher than the one obtained on the CoTiA catalyst and steadily increases as the reaction temperature rises. The excellent FTS catalytic performance of the $\mathrm{TiO}_{2}$-promoted hierarchically structured catalyst could be attributed to the better dispersion of cobalt particles in the presence of $\mathrm{TiO}_{2}$ nanoparticles according to ${ }^{59} \mathrm{Co}$ NMR (see below) and HR-TEM analysis, and also to the high accessibility of the composite surface area according to the $\mathrm{N}_{2}$ adsorption-desorption.

Fig. 6 presents the FTS reaction performance over $120 \mathrm{~h}$ on the hierarchically structured CoTiCNTA catalyst. It is mentionable that the catalyst had already run for more than $200 \mathrm{~h}$ under different

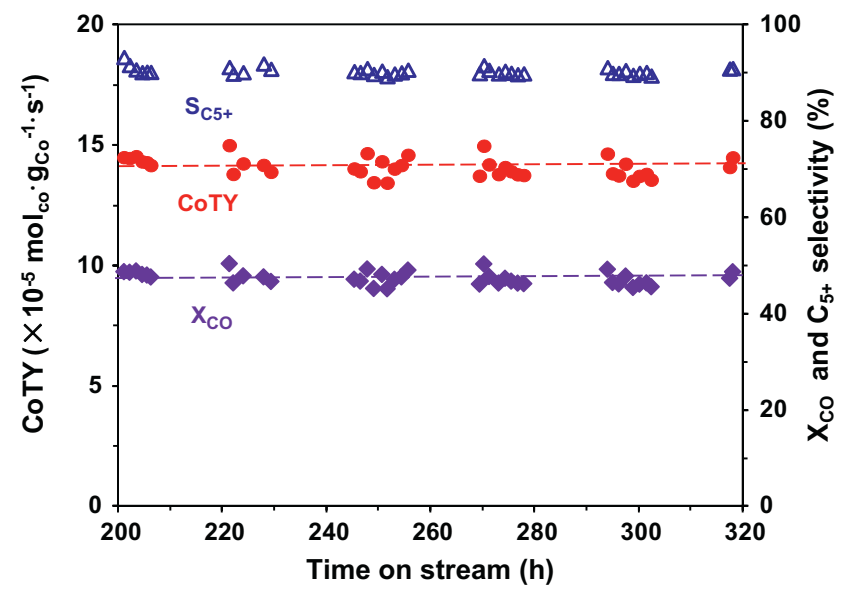

Fig. 6. Catalytic performance of CoTiCNTA catalyst as a function of time on stream under severe reaction condition. Reaction conditions: $\mathrm{H}_{2} / \mathrm{CO}$ molar ratio $=2$, pure syngas, total pressure $=40 \mathrm{bar}, T=230^{\circ} \mathrm{C}, \mathrm{GHSV}(\mathrm{STP})=7200 \mathrm{~mL} \mathrm{~g}_{\text {cat }}^{-1} \mathrm{~h}^{-1}$.

reaction conditions before the present test. The $\mathrm{CO}$ conversion $\left(X_{\mathrm{CO}}\right)$ remains stable at around $47 \%$ for the whole duration of the test which confirms the excellent stability of the catalyst over prolonged reaction time. The high stability of the FTS activity indicates that deactivation linked to cobalt surface oxidation and excessive sintering are unlikely to occur over the current materials under the reaction conditions used in the present work [8,54]. The $C_{5+}$ selectivity is also extremely high at around $90 \%$, demonstrating that the nature of the active phase is not modified during the reaction.

\subsection{Cobalt microstructure analysis by ${ }^{59} \mathrm{Co}$ NMR technique}

To get a deeper insight into the relationship between the FTS activity and the microstructure of the cobalt active sites, zero field spin-echo ${ }^{59}$ Co NMR analysis is carried out on the tested catalysts $[32,40,41,55]$. It is worth noting that particle sizes measured from XRD and low-resolution TEM are not reflecting the real crystal sizes of the active phase. In addition to the comments given in the previous paragraph about the XRD and NMR determined average particle size, it can also be remarked that small cobalt crystals could aggregate to a large particle with big voids, which cannot be detected by the techniques mentioned above. In case of broad size distribution, as for the samples under investigation, the X-ray pattern will be dominated by the few big particles that will involve a large part of the total mass of Co. These particles have a small surface-to-volume ratio and will therefore not be very efficient for the 
FTS reaction. Moreover, for the crystalline atomic arrangement in microstructures, a considerable number of defects and stacking faults might be present inside the metal structure without being accurately detected by XRD technique. Indeed, some direct information about the real cobalt crystal particles size and structure could be obtained by high-resolution TEM analysis. However, due to the limitation of visual field, only a small part of the active phase is analyzed by this technique. In addition, the statistical analysis by HRTEM is a time-consuming experiment and is not representative of the whole microstructure of the active phase in the catalyst. The real advantage of NMR technique is that it is a bulk technique allowing one to get access to the total metallic phase of cobalt inside the catalyst at a macroscopic scale.

The ${ }^{59}$ Co NMR spectra are measured at $2,4.2$, and $77 \mathrm{~K}$ on different catalysts and the corresponding results are displayed in Figs. 7 and S7. The NMR intensity is multiplied by the measurement temperature in order to take into account the regular $1 / T$ dependence of the NMR intensity. Therefore, the decrease of the NMR signal with the increase of the measurement temperature directly shows a decrease of the amount of measured ferromagnetic Co atoms. Indeed, if superparamagnetic Co particles (particles for which the magnetization direction is not fixed within the NMR measurement time) are present in the sample at a given measurement temperature, the signal of these superparamagnetic particles vanishes from the NMR spectra [41,56]. As such NMR intensities versus temperature give identical information as the one obtained through thermoremanent measurements as described by Denardin et al. [57]. This is a standard procedure for analyzing the size distribution of magnetic nanoparticles. What makes our methodology specifically
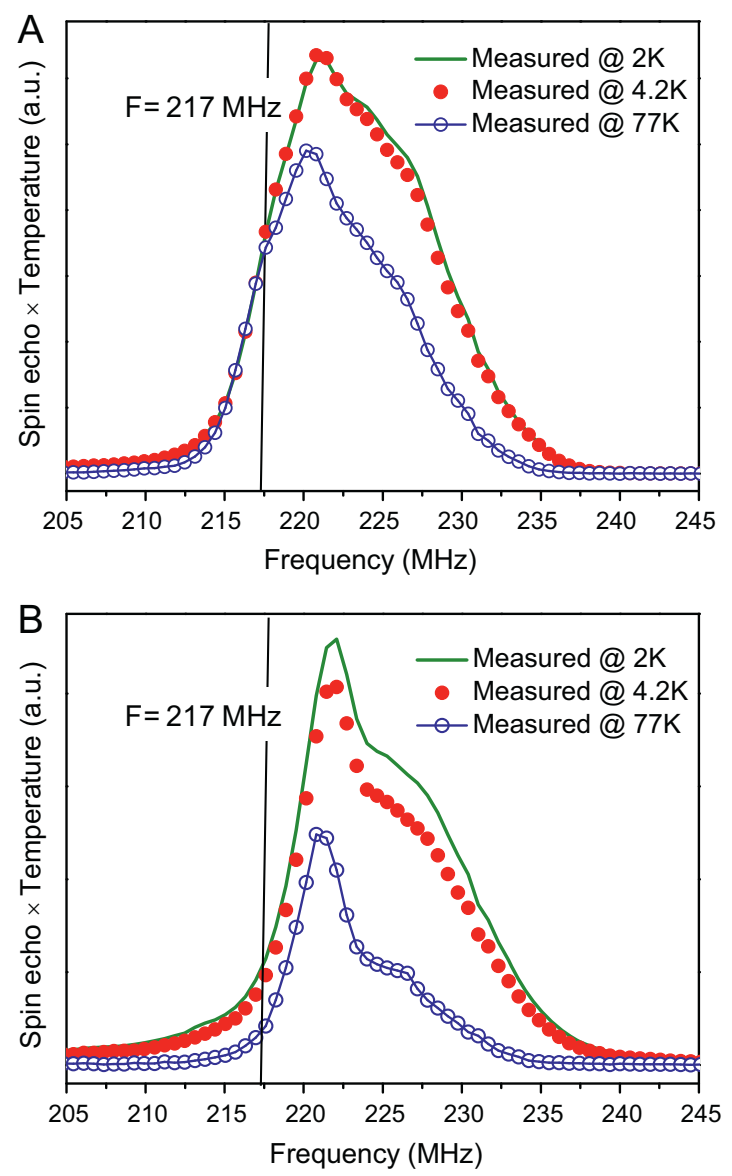

Fig. 7. ${ }^{59}$ Co zero field NMR spectra recorded at 2, 4.2, and $77 \mathrm{~K}$, respectively, (A) CoA and (B) CoTiCNTA catalysts after FTS test decorated with solid wax. useful is that since when the NMR measurement temperature increases the size limit below which the co particles become superparamagnetic increases also, it is therefore possible to select the size of the measured particles through the NMR measurement temperature: the higher the NMR measurement temperature, the larger the observed particles. Thanks to the NMR sensitivity to the Co local crystallographic structure, it is therefore possible to analyze the evolution of the particles structure within their size (see Supplementary information for the detailed relationship between measurement temperature and particle size).

Fig. 7 shows that the NMR intensity decreases for most of the frequency range. However, it can be noticed that the intensity close to $217 \mathrm{MHz}$ does stay unchanged with the increase of the NMR measurement temperature. This resonance frequency corresponds to bulk (>60 nm) face centered cubic (fcc) Co crystals [56,58]. This suggests that a large number of $\mathrm{Co}$ atoms are situated in large fcc particles. The resonance frequency shows that the particles have magnetically a multi-domain structure. This can be obtained only if their size is typically larger than about $60 \mathrm{~nm}$. The fact that the NMR intensity in the $217 \mathrm{MHz}$ range is identical for all the measurement temperatures is consistent with the presence of magnetically multi-domain particles since such large particles cannot become superparamagnetic at any of the NMR measurement temperatures. There is no pronounced NMR peak at $217 \mathrm{MHz}$ for the cobalt deposited on hierarchically structured catalysts, neither for CoCNTA nor for CoTiCNTA catalysts. Therefore, one can conclude that these catalysts do not possess any fcc Co particles larger than $60 \mathrm{~nm}$. In addition, it can be noted that the NMR intensity decreases also much faster when the measurement temperature is increased for the samples containing CNTs. These qualitative observations show by themselves that the Co particles in the hierarchically structured catalysts are much smaller than in the CNTfree catalysts. This could be attributed to the fact that the CNTbased composite, pure and doped with $\mathrm{TiO}_{2}$, offered higher specific area and medium metal-support interaction leading to a higher cobalt dispersion with smaller cobalt particles. As it can be seen, the NMR spectra have a similar shape for both the hierarchically structured $\mathrm{TiO}_{2}$-promoted and $\mathrm{TiO}_{2}$-free catalysts (Figs. $7 \mathrm{~B}$ and S7). These results indicate that $\mathrm{TiO}_{2}$ has no influence on the cobalt particles crystallographic structure, but only participates in the enhancement of the cobalt nanoparticles dispersion (see below) and even introduces defect sites in the metal particles $[59,60]$.

Quantitative information can be obtained from the analyses of the NMR integral intensity versus the measurement temperature, such as the fraction of Co atoms involved in particles with different blocking temperature ranges (different size ranges can be computed in Fig. 8A). The blocking temperature range linked to a specific size of particle is strongly dependent on the shape of the particle that is chosen (spheres, half-spheres, flat rafts...), but this does not affect the relative distributions as given in Fig. $8 \mathrm{C}$ and D. An order of magnitude of these sizes can be given: $3-4 \mathrm{~nm}$ for the blocking temperature between 2 and $4.2 \mathrm{~K} ; 4-10 \mathrm{~nm}$ for blocking temperature between 4.2 and $77 \mathrm{~K}$ and more than $10 \mathrm{~nm}$ for the blocking temperature above $77 \mathrm{~K}$ (Fig. 8B). In Fig. 8A, the sum of the contribution of all the temperature ranges add up to $100 \%$ for all the samples, since in all the samples, the total amount of Co atoms is identical. Assuming that all particles have the same shape, it is then possible to work out the size distribution of the particles (see Supplementary information for details). This is the traditional way of analyzing such particle distributions. In Fig. 8C, we have to take into consideration that the total amount of Co particles in each sample will depend on the size of particles that is obtained by the fabrication process. Indeed, for the same amount of Co atoms, the number of particles produced is much smaller if the Co atoms are clustered in large particles than in small particles. This is taken into account in Fig. 8C. The number of particles 

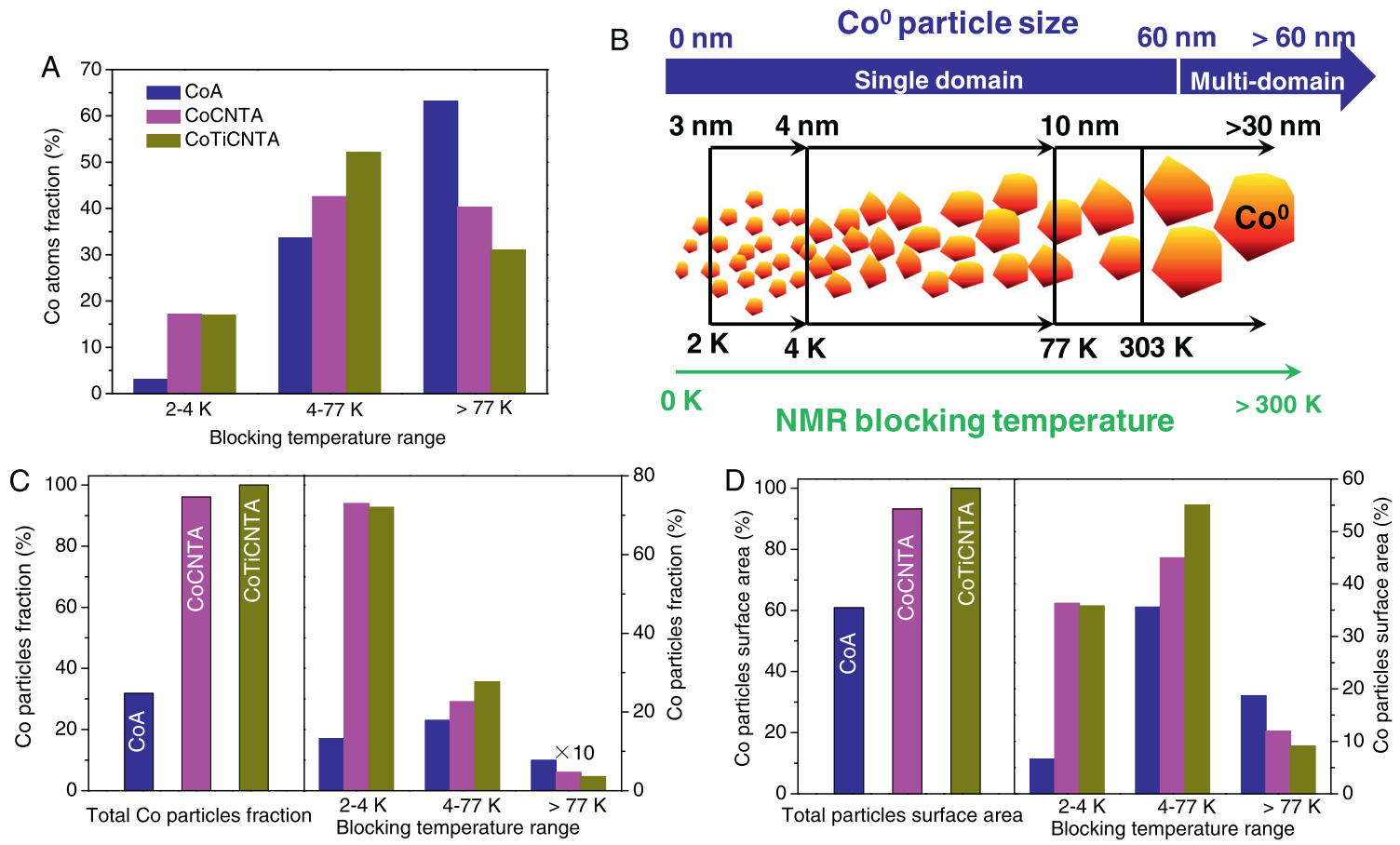

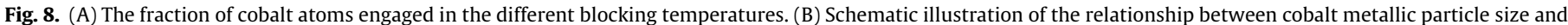

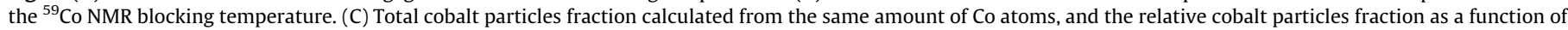

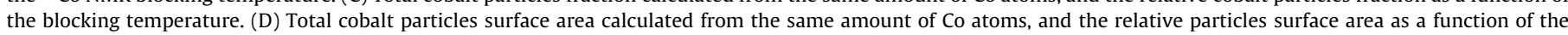

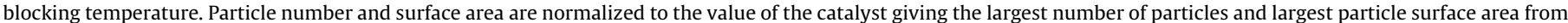
the same cobalt loading.

produced is normalized to $100 \%$ only for the sample producing the largest number of particles. The same normalization factor is then used for the other samples so that Fig. 8C allows not only comparing the shape of the size distribution of the samples but also the absolute number of particles obtained in each sample. Indeed, in Fig. 8C, we can obtain the following information: the left panel shows the total number of particles obtained for each sample, normalized to CoTiCNTA since it is the sample showing the largest number of particles, and the right panel shows how these particles are split into the 3 temperature ranges. The left panel of Fig. 8C shows that the presence of CNT produces about 3 times more particles (for the same mass of Co atoms) than CoA. The right panel shows that the size distribution does look completely different from the atom distribution. Indeed, from the atom distribution in Fig. 8A, one can see that about $30-60 \%$ of the Co atoms are involved into large particles (blocking temperature $>77 \mathrm{~K}$ ), but it is worthy to note that these large particles represent less than $1 \%$ of the number of particles produced in the catalyst. A careful look at right panel of Fig. 8C also shows that both samples containing CNTs have similar size distributions. However, CoTiCNTA that shows the largest total number of particles actually presents a larger amount of particles of the small size $(4-10 \pm 1 \mathrm{~nm}, 4.2-77 \mathrm{~K}$ temperature range) than CoCNTA.

The catalytic reaction generally occurs at the surface of the particles, therefore we believe that the real information needs that to be considered is the surface area offered by the Co particles for the reaction as shown in Fig. 8D. The normalization process is similar to the one used for the particle size distribution in Fig. 8C. The conclusions in Fig. $8 \mathrm{C}$ and D show that the CNTs significantly increase the amount of available cobalt particles and surface area, which in turn leads to a higher FTS activity $[30,61]$. The large particles (blocking temperature higher than $77 \mathrm{~K}$ corresponding to particles from $10 \mathrm{~nm}$ to $30 \mathrm{~nm}$ or larger) only offer less than $20 \%$ of activity sites in total cobalt particles (Fig. 8D). The advantage of CoTiCNTA over CoCNTA in the average size range $(4-10 \pm 1 \mathrm{~nm})$ is even more evident in Fig. 8D, where it can be seen that in this range the available surface is about 10\% larges in CoTiCNTA than in CoCNTA.

Since determining particle size distribution through temperature dependent NMR measurements has been performed for the first time, for sake of comparison, size distribution from high-resolution TEM is also performed on the CoCNTA sample and the results are displayed in Fig. 9. The size distribution shows that the sizes of most cobalt particles in this sample are around 2$8 \mathrm{~nm}$. This result is in consistent with the result from ${ }^{59}$ Co NMR measurement. It has to be mentioned that for TEM measurement, the size distribution of the metal nanoparticles is essentially based on high-resolution TEM images, due to the fact that at low-resolution smaller cobalt particles are difficult to identify. Therefore statistical analysis has only been performed on restricted areas of the sample (Fig. S8). The small cobalt particles around $5 \mathrm{~nm}$ can be identified by high-resolution TEM images (as shown in Fig. S8C and D). Statistical TEM analysis has been performed in several areas of the sample and the cobalt particle size distribution was calculated from more than hundred particles. According to the results, one can conclude that the Co particle size distribution derived from the ${ }^{59} \mathrm{Co}$ NMR is very similar to that was determined by HR-TEM with an advantage of being a macroscopic technique for this former one.

\section{5. $\mathrm{TiO}_{2}$-promoted hierarchical catalyst under severe FTS reaction conditions}

The catalytic performance of the CoTiCNTA catalyst is further evaluated under more severe FTS reaction conditions, i.e., high reaction temperature $\left(T=245^{\circ} \mathrm{C}\right)$, high pressure (40 bar), and high space velocity (GHSV (STP) $=9600 \mathrm{~mL} \mathrm{~g}_{\text {cat }}^{-1} \mathrm{~h}^{-1}$ ). As shown in Fig. 10, the $\mathrm{TiO}_{2}$-promoted hierarchical catalyst gives approximately $84.5 \%$ selectivity to $C_{5+}$ at $47.4 \%$ CO conversion. The cobalt 

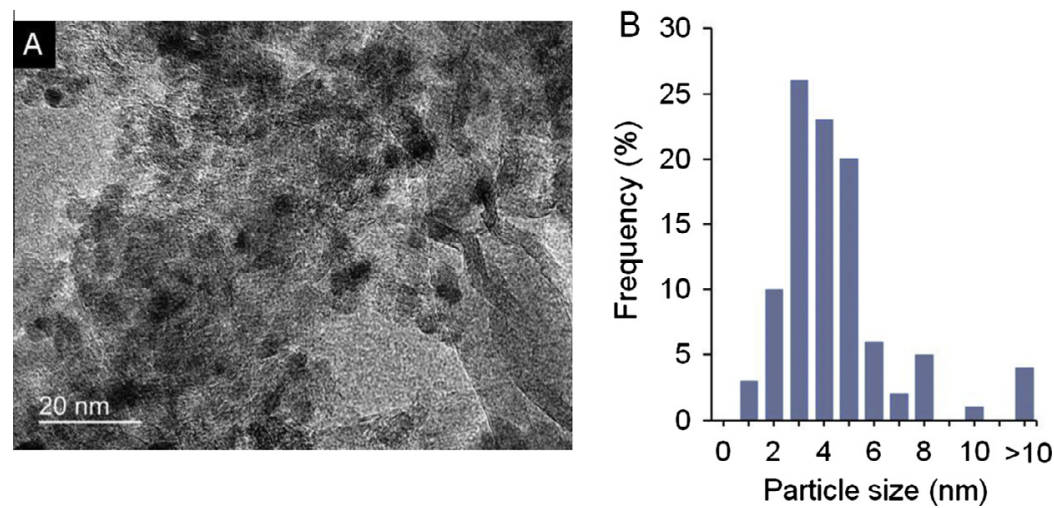

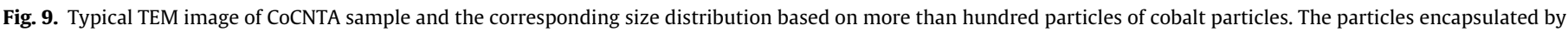
CNTs are not accounted for the size distribution since they are irresponsible for the reaction as previously discussed.

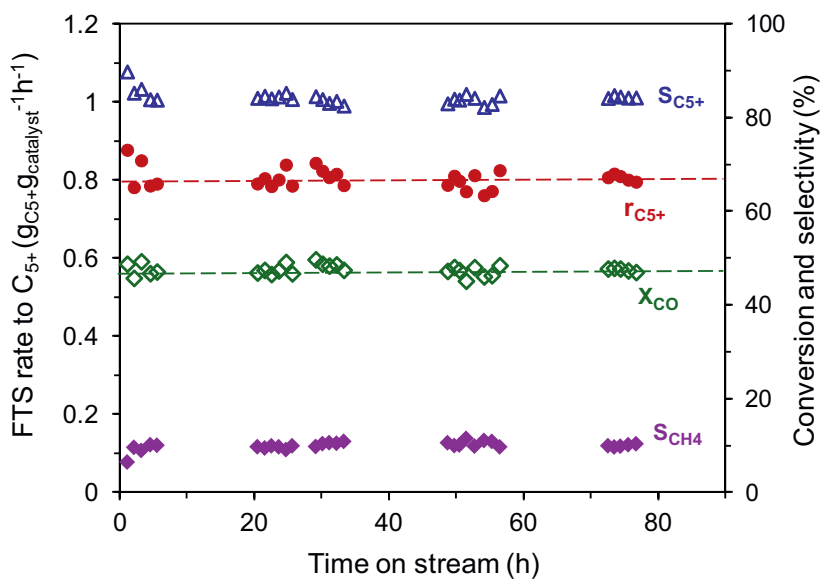

Fig. 10. Catalytic activity as a function of time of hierarchical cobalt-based catalyst (CoTiCNTA) under severe FTS reaction. Reaction conditions: $T=245^{\circ} \mathrm{C}$, GHSV $(\mathrm{STP})=9600 \mathrm{~mL} \mathrm{~g}_{\text {cat }}^{-1} \mathrm{~h}^{-1}$, total pressure $=40 \mathrm{bar}, 2.5 \mathrm{~g}$ catalyst diluted with $7.5 \mathrm{~g}$ $\mathrm{SiC}, \mathrm{H}_{2} / \mathrm{CO}=2$.

time yield (CoTY) is $18.8 \times 10^{-5} \mathrm{~mol}_{\mathrm{co}} \mathrm{g}_{\mathrm{Co}}^{-1} \mathrm{~s}^{-1}$ and FTS rate expressed in terms of the weight of long-chain hydrocarbon formed per gram of catalyst per hour $\left(g_{\mathrm{c} 5}+g_{c a t}^{-1} h^{-1}\right)$ is around $0.80 \mathrm{~g}_{\mathrm{C} 5+} \mathrm{g}_{\text {cat }}^{-1} \mathrm{~h}^{-1}$, which is the best result among all the noble-free cobalt-based catalysts previously reported in the literature, including the cobalt on CNF and CNT catalysts $[17,43]$. It is also worthy to note that the $\mathrm{C}_{5+}$ selectivity remains relatively high under these severe reaction conditions, especially with the high reaction temperature, thus highlighting the fact that CNTs introduced in the skeleton of support in the FTS reaction allow the catalyst to maintain high selectivity toward long-chain hydrocarbons.

The products distribution is expressed as chain growth probability factors $(\alpha)$ calculated from the linear portion of the hydrocarbons using the Anderson-Schulz-Flory (ASF) model [51,62]. The product distribution is obtained from mass balance after FTS reaction by analyzing the solid wax phase products. The chain growth factor is calculated according to the following equation:

$W_{n} / n=(1-\alpha)^{2} \alpha^{(n-1)}$

where $W_{n}$ is the weight fraction of hydrocarbon molecules containing $n$ carbon atoms. $\alpha$ is the chain growth probability. When $\alpha$ is equal to 0 , all the $\mathrm{CO}$ molecules are converted to $\mathrm{CH}_{4}$; while when $\alpha$ is equal to 1 , all the $\mathrm{CO}$ molecules are converted to liquid hydrocarbons.
The ASF plots show that the CoTiCNTA catalyst provides a relatively high $\alpha$ value of about 0.89 (Fig. 11), even under severe conditions. The relative high $\alpha$ value is in good agreement with the relatively low methane selectivity $(<10 \%)$ obtained on the CoTiCNTA catalyst. This high $\alpha$ value on $\mathrm{TiO}_{2}$-promoted hierarchically structured catalyst could be attributed to the open structure of tested catalyst that favors the diffusion of reactant toward the active site, and also to the thermal conductivity of the CNTs on the support that prevents local hot spot formation $[24,32,63]$.

\section{Discussion}

The introduction of a layer of CNTs on the $\alpha-\mathrm{Al}_{2} \mathrm{O}_{3}$ leads to a significant increase in the effective surface area of the composite support which contributes both to the improvement of the cobalt dispersion compared to the low surface area $\alpha-\mathrm{Al}_{2} \mathrm{O}_{3}$ and also to the accessibility of the reactant to the active site. The characterization and catalytic results show that the introduction of both CNTs and CNTs promoted with $\mathrm{TiO}_{2}$ have a pronounced effect on the FTS activity of the catalysts. The cobalt turnover frequencies (TOF, reaction rates normalized by the total number of cobalt atoms on the surface of the cobalt metal particles) of the different catalysts are presented in Table 3. They confirm the high activity of the CoTiCNTA ( $10 \mathrm{wt} . \%$ of $\mathrm{TiO}_{2}$ ) catalyst compared to that of the $\mathrm{TiO}_{2}$-free alumina-based catalyst, i.e., $48.7 \times 10^{-3} \mathrm{~s}^{-1}$ versus $37.2 \times 10^{-3} \mathrm{~s}^{-1}$. It seems that the $\mathrm{TiO}_{2}$ promoter plays an important role to allow the formation of small cobalt particles with metal-support interaction not too high to allow the complete

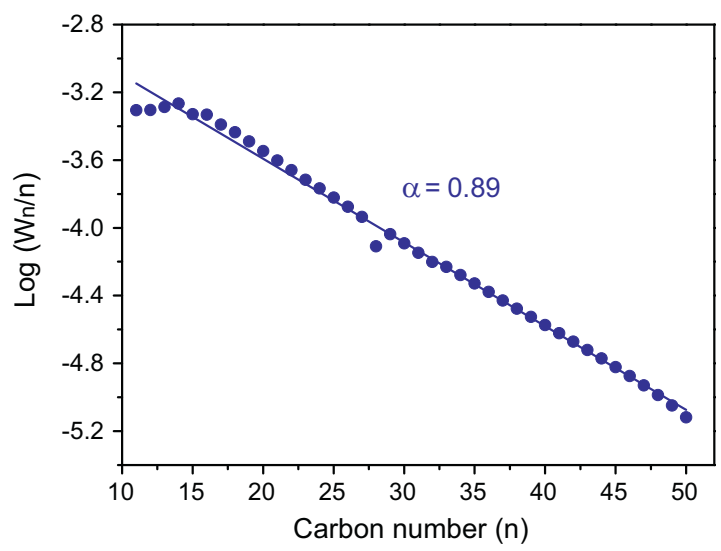

Fig. 11. Anderson-Schulz-Flory plot for $\mathrm{TiO}_{2}$-promoted hierarchical cobalt-based catalyst (COTiCNTA) under severe FTS reaction conditions. 
reduction of the cobalt particles but also high enough to prevent cobalt diffusion and subsequence agglomeration. Similar results have already been reported by Venezia et al. [35] who showed the benefit of $\mathrm{TiO}_{2}$ to prepare cobalt-based catalyst in which high dispersion and better long-chain hydrocarbon selectivity were observed. In the present work, the strong metal-support interaction (SMSI) between $\mathrm{TiO}_{2}$ and cobalt seems not to be present according to TEM analysis, where no trace of $\mathrm{TiO}_{x}$ overlayers was observed on the cobalt surface.

The correlation between the small cobalt particle size and the FTS performance was investigated in detail in the present work through the extensive use of ${ }^{59} \mathrm{Co}$ NMR technique. In the samples containing CNTs, all the particles are single domain, so the main line can be easily attributed to $f c c \mathrm{Co}$. The higher frequency shoulders also evidence the presence of hexagonal close-packed $(h c p)$ Co as well as stacking faults $[58,64]$. The spectrum of the CoA sample is much more complex since contributions of single domain and multi-domain particles are superimposed. However, from the ratio of the high to low frequency NMR intensities, it can be inferred that the particles have a more $h c p$-like structure than in the samples containing CNTs. Finally, Figs. 7B and S7 indicate that NMR spectra have very similar shapes over whole the blocking temperature range considered. This means that the crystallographic structure, as well as the number of stacking faults, are similar for the particles whatever their sizes. Therefore, one can conclude that the FTS activity is solely influenced by the size distribution of the Co particles on these two hierarchical catalysts (CoCNTA and CoTiCNTA). As mentioned above that the total cobalt particles surface area increases by about $10 \%$ after introduction of $\mathrm{TiO}_{2}$, which highlights the efficiency of the $\mathrm{TiO}_{2}$ phase on the dispersion of the cobalt phase (Fig. 8C and D). The largest increase in total particles and atoms surface area is due to the particles ranging from 4 to $10 \pm 1 \mathrm{~nm}$, which means that such small particles $\left(4-10 \mathrm{~nm},{ }^{59} \mathrm{Co}\right.$ NMR blocking temperature range from $4 \mathrm{~K}$ to $77 \mathrm{~K}$ ) play key role in the enhancement of the FTS activity after the introduction of $\mathrm{TiO}_{2}$ NPs.

The results obtained in the present work about the direct influence of the cobalt particle size on the FTS performance are relatively close to those reported previously by de Jong and coworkers [17]. Indeed, de Jong and co-workers [17] have come to the conclusion that the activity and selectivity in the Fischer-Tropsch reaction are strongly dependent on cobalt particle size for catalysts using carbon nanofibers as support. They have suggested that, for low pressure conditions ( 1 bar), average cobalt sizes smaller that $6 \mathrm{~nm}$ are less efficient, while at high pressure conditions ( $35 \mathrm{bar}$ ), the upper average size limit is $8 \mathrm{~nm}$. Prieto et al. [65] demonstrated by in situ spectroscopic measurements that the catalytic activity decreased when cobalt metallic particle size was smaller than $10 \mathrm{~nm}$ on the surface of functionalized zeolite supports. According to our NMR results, we speculate that the small particles $(4-10 \mathrm{~nm})$ have multiple active sites depending on the preparation and materials used as support. Goodman and co-workers [66] have also mentioned that Co particles in the range $3.5-10.5 \mathrm{~nm}$ show higher catalytic activity and low methane selectivity in the FTS process. They proposed that the divergence in particle size range compared to the previous research work [65] was due to the difference in catalyst preparation and complexity of the FTS process itself. Indeed, the results reported by den Breejen et al. [67] are issued from cobalt nanoparticles deposited on carbon nanofibers with peculiar prismatic planes, and thus, some specific interaction could also influence the FTS performance compared to the results reported on cobalt supported on other supports such as silica, alumina, or titania. Johnson et al. [68] have reported that FTS can be structure-insensitive under certain reaction conditions and the FTS activity and selectivity were function of the chemical nature of the support instead of the cobalt dispersion and size. Similar results have also been reported by Borg et al. [69] who observed no direct relationship between the FTS activity and the cobalt particle size. From these results, one can stated that cobalt particle size in the range of $4-10 \pm 1 \mathrm{~nm}$ could significantly contribute to an improvement of the FTS activity despite some additional investigations are needed to clarify this fundamental issue.

\section{Conclusion}

In summary, we have reported the synthesis of a hierarchical $\mathrm{TiO}_{2} / \mathrm{CNT}-\alpha-\mathrm{Al}_{2} \mathrm{O}_{3}$ composite consisting of single crystal $\mathrm{TiO}_{2}$ nanoparticles deposited on macroscopically shaped $\alpha-\mathrm{Al}_{2} \mathrm{O}_{3}$ decorated with a layer of carbon nanotubes. The obtained composite possesses high specific surface area and fully accessible effective surface, which significantly improve the cobalt nanoparticles dispersion and accessibility of the reactant toward the active site, exhibiting high and stable FTS performance. The FTS rate toward long-chain hydrocarbon $\left(\mathrm{C}_{5+}\right)$ on the $\mathrm{Co} / \mathrm{TiO}_{2} / \mathrm{CNT}-\alpha-\mathrm{Al}_{2} \mathrm{O}_{3}$ (CoTiCNTA) can reach $0.64 \mathrm{~g}_{\mathrm{C} 5+} \mathrm{g}_{\text {cat }}^{-1} \mathrm{~h}^{-1}$ along with a selectivity toward $\mathrm{C}_{5+}$ as high as $90 \%$. Moreover, under severe FTS reaction conditions (high reaction temperature, high pressure and flow rate), the CoTiCNTA catalyst achieves a FTS rate to $\mathrm{C}_{5+}$ of about $0.80 \mathrm{~g}_{\mathrm{C} 5+} \mathrm{g}_{\text {cat }}^{-1} \mathrm{~h}^{-1}$, along with a long-chain hydrocarbon selectivity of $85 \%$, which can be pointed out as the most outstanding noble promoter-free catalyst for the FTS reaction.

The high catalytic performance in the FTS reaction is attributed to the presence of $\mathrm{TiO}_{2}$-promoted surface which displays a high interaction with the deposited cobalt phase leading to the formation of small cobalt particles in the range of 4 to $10 \mathrm{~nm}$. The high activity is also linked to the effective surface area of CNT network on the catalyst surface that provides high accessibility of the reactant toward the active sites. On the other hand, the nanoscopic size of the carbon nanotubes also supplies short diffusion pathway for product escaping. The cobalt particle size and structure are also extensively characterized by a ${ }^{59}$ Co NMR technique and the comparison of the catalytic results and the NMR data allows us to clearly evidence a direct relationship between the cobalt particle size and the FTS performance.

The hierarchical catalyst developed in the present work also exhibit an extremely high stability, compared to other traditional FTS catalysts, as a function of time on stream, thanks to the medium interaction between the $\mathrm{TiO}_{2}$ promoter and cobalt NPs. Such stability is an advantage when the catalyst is applied for the BTL process, where some impurities or moisture could be detrimental to the catalyst life-time in normal cases.

\section{Acknowledgments}

Y.F. Liu would like to thank the China Scholarship Council (CSC) for the PhD grant during his stay at the ICPEES in the University of Strasbourg. The SEM/TEM and ${ }^{59}$ Co NMR experiments were carried out at the facilities of IPCMS (UMR 7504 CNRS). The authors kindly acknowledge $F$. Vigneron (experimental assistance), T. Romero (SEM), and P. Bernhardt (XPS) from ICPEES. Drs. Ch. Pham, W. Baaziz, V. Caps and A.Y. Khodakov are gratefully acknowledged for the helpful discussions.

\section{Appendix A. Supplementary material}

Supplementary data associated with this article can be found, in the online version, at http://dx.doi.org/10.1016/j.jcat.2014.08.006. 


\section{References}

[1] K. Aleklett, M. Hook, K. Jakobsson, M. Lardelli, S. Snowden, B. Soderbergh, The peak of the oil age - analyzing the world oil production reference scenario in world energy outlook 2008, Energy Policy 38 (2010) 1398-1414.

[2] G. Centi, S. Perathoner, Carbon nanotubes for sustainable energy applications, ChemSusChem 4 (2011) 913-925.

[3] G.W. Huber, S. Iborra, A. Corma, Synthesis of transportation fuels from biomass: chemistry, catalysts, and engineering, Chem. Rev. 106 (2006) 4044-4098.

[4] J.R. Rostrup-Nielsen, Making fuels from biomass, Science 308 (2005) 1421 1422.

[5] A.Y. Khodakov, W. Chu, P. Fongarland, Advances in the development of novel cobalt Fischer-Tropsch catalysts for synthesis of long-chain hydrocarbons and clean fuels, Chem. Rev. 107 (2007) 1692-1744.

[6] E. de Smit, B.M. Weckhuysen, The renaissance of iron-based Fischer-Tropsch synthesis: on the multifaceted catalyst deactivation behaviour, Chem. Soc. Rev. 37 (2008) 2758-2781.

[7] A.M. Saib, D.J. Moodley, I.M. Ciobica, M.M. Hauman, B.H. Sigwebela, C.J. Weststrate, J.W. Niemantsverdriet, J. van de Loosdrecht, Fundamental understanding of deactivation and regeneration of cobalt Fischer-Tropsch synthesis catalysts, Catal. Today 154 (2010) 271-282.

[8] N.E. Tsakoumis, M. Ronning, O. Borg, E. Rytter, A. Holmen, Deactivation of cobalt based Fischer-Tropsch catalysts: a review, Catal. Today 154 (2010) 162 182.

[9] H.M.T. Galvis, J.H. Bitter, C.B. Khare, M. Ruitenbeek, A.I. Dugulan, K.P. de Jong, Supported iron nanoparticles as catalysts for sustainable production of lower olefins, Science 335 (2012) 835-838.

[10] Q.H. Zhang, J.C. Kang, Y. Wang, Development of novel catalysts for FischerTropsch synthesis: tuning the product selectivity, ChemCatChem 2 (2010) 1030-1058.

[11] R. Luque, A.R. de la Osa, J.M. Campelo, A.A. Romero, J.L. Valverde, P. Sanchez, Design and development of catalysts for Biomass-To-Liquid-Fischer-Tropsch (BTL-FT) processes for biofuels production, Energy Environ. Sci. 5 (2012) 51865202.

[12] H.F. Xiong, Y.H. Zhang, S.G. Wang, J.L. Li, Fischer-Tropsch synthesis: the effect of $\mathrm{Al}_{2} \mathrm{O}_{3}$ porosity on the performance of $\mathrm{Co} / \mathrm{Al}_{2} \mathrm{O}_{3}$ catalyst, Catal. Commun. 6 (2005) 512-516.

[13] A.Y. Khodakov, Fischer-Tropsch synthesis: relations between structure of cobalt catalysts and their catalytic performance, Catal. Today 144 (2009) $251-$ 257.

[14] E. Iglesia, Design, synthesis, and use of cobalt-based Fischer-Tropsch synthesis catalysts, Appl. Catal. A - Gen. 161 (1997) 59-78.

[15] R. Oukaci, A.H. Singleton, J.G. Goodwin, Comparison of patented CoF-T catalysts using fixed-bed and slurry bubble column reactors, Appl. Catal. A Gen. 186 (1999) 129-144.

[16] S. Storsaeter, B. Totdal, J.C. Walmsley, B.S. Tanem, A. Holmen, Characterization of alumina-, silica-, and titania-supported cobalt Fischer-Tropsch catalysts, J. Catal. 236 (2005) 139-152.

[17] G.L. Bezemer, J.H. Bitter, H.P.C.E. Kuipers, H. Oosterbeek, J.E. Holewijn, X.D. Xu, F. Kapteijn, A.J. van Dillen, K.P. de Jong, Cobalt particle size effects in the Fischer-Tropsch reaction studied with carbon nanofiber supported catalysts, J. Am. Chem. Soc. 128 (2006) 3956-3964.

[18] W. Chu, L.N. Wang, P.A. Chernavskii, A.Y. Khodakov, Glow-discharge plasmaassisted design of cobalt catalysts for Fischer-Tropsch synthesis, Angew. Chem. Int. Ed. 47 (2008) 5052-5055.

[19] J. Yang, Y. Qi, J. Zhu, Y.-A. Zhu, D. Chen, A. Holmen, Reaction mechanism of CO activation and methane formation on Co Fischer-Tropsch catalyst: a combined DFT, transient, and steady-state kinetic modeling, J. Catal. 308 (2013) 37-49.

[20] Y. Liu, O. Ersen, C. Meny, F. Luck, C. Pham-Huu, Fischer-Tropsch reaction on thermally conductive and reusable silicon carbide support, ChemSusChem 7 (2014) 1218-1239.

[21] X.W. Zhu, X.J. Lu, X.Y. Liu, D. Hildebrandt, D. Glasser, Study of radial heat transfer in a tubular Fischer-Tropsch synthesis reactor, Ind. Eng. Chem. Res. 49 (2010) 10682-10688.

[22] R. Myrstad, S. Eri, P. Pfeifer, E. Rytter, A. Holmen, Fischer-Tropsch synthesis in a microstructured reactor, Catal. Today 147 (2009) S301-S304.

[23] M. Lacroix, L. Dreibine, B. de Tymowski, F. Vigneron, D. Edouard, D. Begin, P. Nguyen, C. Pham, S. Savin-Poncet, F. Luck, M.J. Ledoux, C. Pharn-Huu, Silicon carbide foam composite containing cobalt as a highly selective and re-usable Fischer-Tropsch synthesis catalyst, Appl. Catal. A - Gen. 397 (2011) 62-72.

[24] A. Martinez, G. Prieto, J. Rollan, Nanofibrous gamma- $\mathrm{Al}_{2} \mathrm{O}_{3}$ as support for Cobased Fischer-Tropsch catalysts: pondering the relevance of diffusional and dispersion effects on catalytic performance, J. Catal. 263 (2009) 292-305.

[25] C.C. Ma, N. Yao, Q. Han, X.N. Li, Synthesis and application of gamma- $\mathrm{Al}_{2} \mathrm{O}_{3}$ supported CoRu-based Fischer-Tropsch catalyst, Chem. Eng. J. 191 (2012) 534-540.

[26] Y.-H. Chin, J. Hu, C. Cao, Y. Gao, Y. Wang, Preparation of a novel structured catalyst based on aligned carbon nanotube arrays for a microchannel FischerTropsch synthesis reactor, Catal. Today 110 (2005) 47-52.

[27] J.J. Delgado, R. Vieira, G. Rebmann, D.S. Su, N. Keller, M.J. Ledoux, R. Schlögl, Supported carbon nanofibers for the fixed-bed synthesis of styrene, Carbon 44 (2006) 809-812.

[28] K. Chizari, A. Deneuve, O. Ersen, I. Florea, Y. Liu, D. Edouard, I. Janowska, D. Begin, C. Pham-Huu, Nitrogen-doped carbon nanotubes as a highly active metal-free catalyst for selective oxidation, ChemSusChem 5 (2012) 102-108.
[29] S. Zarubova, S. Rane, J. Yang, Y. Yu, Y. Zhu, D. Chen, A. Holmen, Fischer-Tropsch synthesis on hierarchically structured cobalt nanoparticle/carbon nanofiber/ carbon felt composites, ChemSusChem 4 (2011) 935-942.

[30] Y. Liu, T. Dintzer, O. Ersen, C. Pham-Huu, Carbon nanotubes decorated $\alpha-\mathrm{Al}_{2} \mathrm{O}_{3}$ containing cobalt nanoparticles for Fischer-Tropsch reaction, J. Energy Chem. 22 (2013) 279-289.

[31] J. Zhu, J. Yang, A.H. Lillebo, Y. Zhu, Y.D. Yu, A. Holmen, D. Chen, Compact reactor for Fischer-Tropsch synthesis based on hierarchically structured Co catalysts: towards better stability, Catal. Today 215 (2013) 121-130.

[32] Y. Liu, B. de Tymowski, F. Vigneron, I. Florea, O. Ersen, C. Meny, P. Nguyen, C. Pham, F. Luck, C. Pham-Huu, Titania-decorated silicon carbide-containing cobalt catalyst for Fischer-Tropsch synthesis, ACS Catal. 3 (2013) 393-404.

[33] S.J. Park, S.M. Kim, M.H. Woo, J.W. Bae, K.W. Jun, K.S. Ha, Effects of titanium impurity on alumina surface for the activity of $\mathrm{Co} / \mathrm{Ti}-\mathrm{Al}_{2} \mathrm{O}_{3}$ Fischer-Tropsch catalyst, Appl. Catal. A - Gen. 419 (2012) 148-155.

[34] S. Hinchiranan, Y. Zhang, S. Nagamori, T. Vitidsant, N. Tsubaki, $\mathrm{TiO}_{2}$ promoted $\mathrm{Co} / \mathrm{SiO}_{2}$ catalysts for Fischer-Tropsch synthesis, Fuel Process. Technol. 89 (2008) 455-459.

[35] M. Lualdi, G. Di Carlo, S. Logdberg, S. Jaras, M. Boutonnet, V. La Parola, L.F Liotta, G.M. Ingo, A.M. Venezia, Effect of Ti and Al addition via direct synthesis to SBA-15 as support for cobalt based Fischer-Tropsch catalysts, Appl. Catal. A - Gen. 443 (2012) 76-86.

[36] A.M. Venezia, V. La Parola, L.F. Liotta, G. Pantaleo, M. Lualdi, M. Boutonnet, S. Järås, $\mathrm{Co} / \mathrm{SiO}_{2}$ catalysts for Fischer-Tropsch synthesis; effect of Co loading and support modification by $\mathrm{TiO}_{2}$, Catal. Today 197 (2012) 18-23.

[37] B. Louis, G. Gulino, R. Vieira, J. Amadou, T. Dintzer, S. Galvagno, G. Centi, M.J. Ledoux, C. Pham-Huu, High yield synthesis of multi-walled carbon nanotubes by catalytic decomposition of ethane over iron supported on alumina catalyst, Catal. Today 102 (2005) 23-28.

[38] G. Gulino, R. Vieira, J. Amadou, P. Nguyen, M.J. Ledoux, S. Galvagno, G. Centi, C. Pham-Huu, $\mathrm{C}_{2} \mathrm{H}_{6}$ as an active carbon source for a large scale synthesis of carbon nanotubes by chemical vapour deposition, Appl. Catal. A - Gen. 279 (2005) 89-97.

[39] P.D. Nellist, S.J. Pennycook, Direct imaging of the atomic configuration of ultradispersed catalysts, Science 274 (1996) 413-415

[40] C. Meny, P. Panissod, in: G.A. Webb (Ed.), Modern Magnetic Resonance, Springer, Heidelberg, Germany, 2006.

[41] P. Panissod, C. Meny, Nuclear magnetic resonance investigations of the structure and magnetic properties of metallic multilayers and nanocomposites, Appl. Magn. Reson. 19 (2000) 447-460.

[42] Y.F. Liu, L.D. Nguyen, T. Truong-Huu, Y. Liu, T. Romero, I. Janowska, D. Begin, C. Pham-Huu, Macroscopic shaping of carbon nanotubes with high specific surface area and full accessibility, Mater. Lett. 79 (2012) 128-131.

[43] M. Trepanier, A.K. Dalai, N. Abatzoglou, Synthesis of CNT-supported cobalt nanoparticle catalysts using a microemulsion technique: role of nanoparticle size on reducibility, activity and selectivity in Fischer-Tropsch reactions, Appl. Catal. A - Gen. 374 (2010) 79-86.

[44] B. Erdem, R.A. Hunsicker, G.W. Simmons, E.D. Sudol, V.L. Dimonie, M.S. ElAasser, XPS and FTIR surface characterization of $\mathrm{TiO}_{2}$ particles used in polymer encapsulation, Langmuir 17 (2001) 2664-2669.

[45] E. Dujardin, C. Meny, P. Panissod, J.P. Kintzinger, N. Yao, T.W. Ebbesen, Interstitial metallic residues in purified single shell carbon nanotubes, Solid State Commun. 114 (2000) 543-546.

[46] A. Lapidus, A. Krylova, V. Kazanskii, V. Borovkov, A. Zaitsev, J. Rathousky, A Zukal, M. Jancalkova, Hydrocarbon synthesis from carbon-monoxide and hydrogen on impregnated cobalt catalysts. 1. Physicochemical properties of 10 -percent cobalt alumina and 10-percent cobalt silica, Appl. Catal. 73 (1991) 65-82.

[47] O. Borg, S. Erib, E.A. Blekkan, S. Storsaeter, H. Wigum, E. Rytter, A. Holmen, Fischer-Tropsch synthesis over gamma-calumina-supported cobalt catalysts: effect of support variables, J. Catal. 248 (2007) 89-100.

[48] W. Chu, P.A. Chernavskii, L. Gengembre, G.A. Pankina, P. Fongarland, A.Y. Khodakov, Cobalt species in promoted cobalt alumina-supported FischerTropsch catalysts, J. Catal. 252 (2007) 215-230.

[49] H. Zhang, C. Lancelot, W. Chu, J.P. Hong, A.Y. Khodakov, P.A. Chernavskii, J Zheng, D.G. Tong, The nature of cobalt species in carbon nanotubes and their catalytic performance in Fischer-Tropsch reaction, J. Mater. Chem. 19 (2009) 9241-9249.

[50] D. Schanke, S. Vada, E.A. Blekkan, A.M. Hilmen, A. Hoff, A. Holmen, Study of Ptpromoted cobalt Co hydrogenation catalysts, J. Catal. 156 (1995) 85-95.

[51] S. Logdberg, M. Lualdi, S. Jaras, J.C. Walmsley, E.A. Blekkan, E. Rytter, A. Holmen, On the selectivity of cobalt-based Fischer-Tropsch catalysts: evidence for a common precursor for methane and long-chain hydrocarbons, J. Catal. 274 (2010) 84-98.

[52] P. Nguyen, C. Pham, B. de Tymowski, C. Pham-Huu, F. Luck, France patent 1101704, in: France Patent 11-01704, France, 2011.

[53] A.Y. Khodakov, A. Griboval-Constant, R. Bechara, V.L. Zholobenko, Pore size effects in Fischer Tropsch synthesis over cobalt-supported mesoporous silicas, J. Catal. 206 (2002) 230-241.

[54] K.H. Cats, I.D. Gonzalez-Jimenez, Y.J. Liu, J. Nelson, D. van Campen, F. Meirer, A.M.J. van der Eerden, F.M.F. de Groot, J.C. Andrews, B.M. Weckhuysen, X-ray nanoscopy of cobalt Fischer-Tropsch catalysts at work, Chem. Commun. 49 (2013) 4622-4624.

[55] B. de Tymowski, Y.F. Liu, C. Meny, C. Lefevre, D. Begin, P. Nguyen, C. Pham, D. Edouard, F. Luck, C. Pham-Huu, Co-Ru/SiC impregnated with ethanol as an 
192

Y. Liu et al./Journal of Catalysis 318 (2014) 179-192

effective catalyst for the Fischer-Tropsch synthesis, Appl. Catal. A - Gen. 419 (2012) 31-40.

[56] A.S. Andreev, O.B. Lapina, J.B.D. de Lacaillerie, A.A. Khassin, Effect of alumina modification on the structure of cobalt-containing Fischer-Tropsch synthesis catalysts according to internal-field Co-59 Nmr data, J. Struct. Chem. 54 (2013) S102-S110.

[57] J.C. Denardin, A.L. Brandl, M. Knobel, P. Panissod, A.B. Pakhomov, H. Liu, X.X. Zhang, Thermoremanence and zero-field-cooled/field-cooled magnetization study of $\mathrm{Co}_{x}\left(\mathrm{SiO}_{2}\right)_{1-x}$ granular films, Phys. Rev. B 65 (2002) 064422.

[58] C. Meny, E. Jedryka, P. Panissod, Satellite structure of Co-59 Nmr-spectra in some Co alloys, J. Phys.-Condens. Mater. 5 (1993) 1547-1556.

[59] I. Florea, Y. Liu, O. Ersen, C. Meny, C. Pham-Huu, Microstructural analysis and energy-filtered TEM imaging to investigate the structure-activity relationship in Fischer-Tropsch catalysts, ChemCatChem 5 (2013) 2610-2620.

[60] H. Xiong, M. Moyo, M.A. Motchelaho, Z.N. Tetana, S.M.A. Dube, L.L. Jewell, N.J. Coville, Fischer-Tropsch synthesis: iron catalysts supported on N-doped carbon spheres prepared by chemical vapor deposition and hydrothermal approaches, J. Catal. 311 (2014) 80-87.

[61] N. Fischer, E. van Steen, M. Claeys, Structure sensitivity of the Fischer-Tropsch activity and selectivity on alumina supported cobalt catalysts, J. Catal. 299 (2013) 67-80.

[62] A. Tavakoli, M. Sohrabi, A. Kargari, Application of Anderson-Schulz-Flory (ASF) equation in the product distribution of slurry phase FT synthesis with nanosized iron catalysts, Chem. Eng. J. 136 (2008) 358-363.
[63] S. Rane, O. Borg, J. Yang, E. Rytter, A. Holmen, Effect of alumina phases on hydrocarbon selectivity in Fischer-Tropsch synthesis, Appl. Catal. A - Gen. 388 (2010) 160-167.

[64] M. Malinowska, C. Meny, E. Jedryka, P. Panissod, The anisotropic firstneighbour contribution to the hyperfine field in hexagonal-close-packed Co: a nuclear magnetic resonance study of diluted alloys and multilayers, J. Phys.Condens. Mater. 10 (1998) 4919-4928.

[65] G. Prieto, A. Martinez, P. Concepcion, R. Moreno-Tost, Cobalt particle size effects in Fischer-Tropsch synthesis: structural and in situ spectroscopic characterisation on reverse micelle-synthesised Co/ITQ-2 model catalysts, J. Catal. 266 (2009) 129-144.

[66] Z.J. Wang, S. Skiles, F. Yang, Z. Yan, D.W. Goodman, Particle size effects in Fischer-Tropsch synthesis by cobalt, Catal. Today 181 (2012) 75-81.

[67] J.P. den Breejen, P.B. Radstake, G.L. Bezemer, J.H. Bitter, V. Froseth, A. Holmen, K.P. de Jong, On the origin of the cobalt particle size effects in Fischer-Tropsch catalysis, J. Am. Chem. Soc. 131 (2009) 7197-7203.

[68] B.G. Johnson, C.H. Bartholomew, D.W. Goodman, The role of surface-structure and dispersion in Co hydrogenation on cobalt, J. Catal. 128 (1991) 231-247.

[69] O. Borg, P.D.C. Dietzel, A.I. Spjelkavik, E.Z. Tveten, J.C. Walmsley, S. Diplas, S. Eri, A. Holmen, E. Ryttera, Fischer-Tropsch synthesis: cobalt particle size and support effects on intrinsic activity and product distribution, J. Catal. 259 (2008) 161-164. 